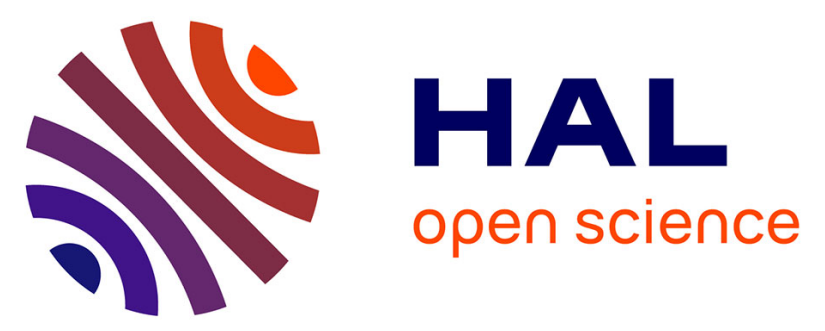

\title{
Improvement of Silicon Nanotweezers Sensitivity for Mechanical Characterization of Biomolecules Using Closed-Loop Control
}

Nicolas Lafitte, Yassine Haddab, Yann Le Gorrec, Hervé Guillou, Momoko Kumemura, Laurent Jalabert, Dominique Collard, Hiroyuki Fujita

\section{To cite this version:}

Nicolas Lafitte, Yassine Haddab, Yann Le Gorrec, Hervé Guillou, Momoko Kumemura, et al.. Improvement of Silicon Nanotweezers Sensitivity for Mechanical Characterization of Biomolecules Using Closed-Loop Control. IEEE/ASME Transactions on Mechatronics, 2015, 20 (3), pp.1418-1427. 10.1109/TMECH.2014.2351415 . hal-03221857

\section{HAL Id: hal-03221857 \\ https://hal.science/hal-03221857}

Submitted on 10 May 2021

HAL is a multi-disciplinary open access archive for the deposit and dissemination of scientific research documents, whether they are published or not. The documents may come from teaching and research institutions in France or abroad, or from public or private research centers.
L'archive ouverte pluridisciplinaire HAL, est destinée au dépôt et à la diffusion de documents scientifiques de niveau recherche, publiés ou non, émanant des établissements d'enseignement et de recherche français ou étrangers, des laboratoires publics ou privés. 


\title{
Improvement of Silicon Nanotweezers Sensitivity for Mechanical Characterization of Biomolecules Using Closed-Loop Control
}

\author{
Nicolas Lafitte, Yassine Haddab, Yann Le Gorrec, Member, IEEE, Hervé Guillou, Momoko Kumemura, \\ Laurent Jalabert, Dominique Collard, Member, IEEE, and Hiroyuki Fujita, Member, IEEE
}

\begin{abstract}
In this paper, we show that closed-loop control can be advantageously used for the characterization of mechanical properties of biomolecules using silicon nanotweezers (SNT). SNT have already been used in open-loop mode for the characterization of mechanical properties of DNA molecules. Up to now, such an approach allows the detection of stiffness variations equivalent to about 15 DNA molecules. Here, it is shown that this resolution is inversely proportional to the resonance frequency of the whole system and that real-time feedback control with state observer can drastically improve the performances of the tweezers used as biosensors. Such improvement is experimentally validated in the case of the manipulation of fibronectin molecules. The results are promising for the accurate characterization of biopolymers such as DNA molecules.
\end{abstract}

Index Terms-Biosensor, MEMS tweezers, parameter detection, sensitivity improvement, state feedback.

\section{INTRODUCTION}

$\mathbf{R}$ ECENT developments in micronano manipulation tools have revealed crucial information on the mechanical behavior of biomolecules [1]-[3]. These manipulations generally performed on a single molecule have given the quantitative data needed to elucidate fundamental biological processes as DNA wrapping [4] and replication [5], or cell cytoskeleton dynamics through actin filament [6], and microtubule mechanical responses [7].

Several methods are already available for performing biological experiments at the molecular level: magnetic tweezers [8], [9], optical tweezers [10], AFM cantilevers [11], and microfibers [2], [12]. A single filamentary macromolecule, such as DNA, is first attached to a surface at one end, and to a bead

Manuscript received October 8, 2012; revised April 9, 2014; accepted June 10, 2014. Recommended by Technical Editor S. O. R. Moheimani. The work of Y. Haddab and Y. Le Gorrec was supported in part by the LABEX ACTION under Grant ANR-11-LABX-01-01 and the NANOROBUST Project (ANR2011 NANO 006).

N. Lafitte, H. Guillou, M. Kumemura, L. Jalabert, and D. Collard are with the LIMMS/CNRS-IIS (UMI 2820), Institute of Industrial Science, The University of Tokyo, Tokyo 153-8505, Japan (e-mail: lafitte@ iis.u-tokyo.ac.jp; herveg@iis.u-tokyo.ac.jp; momo@iis.u-tokyo.ac.jp; jalabert@iis.u-tokyo.ac.jp; collard@iis.u-tokyo.ac.jp).

Y. Haddab and Y. Le Gorrec are with the FEMTO-ST/UFC-ENSMMUTBM-CNRS, 25044 Besançon, France (e-mail: yassine.haddab@ens2m.fr; Yann.Le.Gorrec@ens2m.fr).

H. Fujita is with the Center for International Research on Micromechatronics, Institute of Industrial Science, The University of Tokyo, Tokyo 153-8505, Japan (e-mail: fujita@iis.u-tokyo.ac.jp).

Color versions of one or more of the figures in this paper are available online at http://ieeexplore.ieee.org.

Digital Object Identifier 10.1109/TMECH.2014.2351415 or a flexible cantilever at the other end. Forces or displacements are sensed by optical measurements. Nevertheless, the real-time operation and the routine implementation of these techniques remain difficult to achieve, as they require complex experimental procedures. In this respect, microelectromechanical systems (MEMS) offer an advantage for systematic analysis since accurate molecular level tools (actuator, end effectors, and sensor) can be integrated on a MEMS platform. Furthermore, these devices can be produced at low cost with batch fabrication, as have the microgrippers developed to grab microsized objects [13] or cells [14]. However, up to now, the performances of such tools are not sufficient to deal with single molecule characterization. In previous reports, silicon nanotweezers (SNT) were designed and fabricated to trap DNA molecules [15], [16] and characterize DNA bundles [17] and reactions on DNA [18]. The stiffness of DNA bundles was derived from the open-loop measurement of the mechanical resonance frequency shift. The current sensing resolution is in the range of $1 \mathrm{mN} \cdot \mathrm{m}^{-1}$, which corresponds to approximatively $15 \lambda$-DNA molecules ${ }^{1}$ [20]. This resolution is limited by the design of the tweezers and the noise of the electronic instrumentation. To improve the overall system sensitivity towards lower stiffness, the primary route consists of reducing the tweezers stiffness to bring the sensor and measured object characteristics close to the same range. Unfortunately, such a design would result in a system that would be too fragile to be processed and utilized.

Our approach consists of scaling down the resonance frequency of the closed-loop system to enhance the sensitivity to SNT stiffness change. After a proper identification of the SNT model, the feedback control has been simulated, optimized, and then implemented. This control strategy has been evaluated with thin fibronectin molecular bundles trapped between SNT tips, and we propose to discuss the advantages and the limits of such closed-loop operations.

This paper is organized as follows. Section II describes the tweezers, the sensing principle, and provides an example of monitoring the DNA trapping. The dynamic model of the tweezers is then detailed in Section III-A. The closed-loop control strategy and its potential to improve the system sensitivity are discussed in Sections III-B and III-C. Section IV details the experimental implementation and provides information on fibronectin molecules measurement with different

\footnotetext{
${ }^{1} \lambda$-DNA is DNA of the bacteriophage $\lambda$ having a contour length of $16.4 \mu \mathrm{m}$ and a stiffness in elastic regime of $66 \mu \mathrm{N} \cdot \mathrm{m}^{-1}$ in low ionic solution [19].
} 


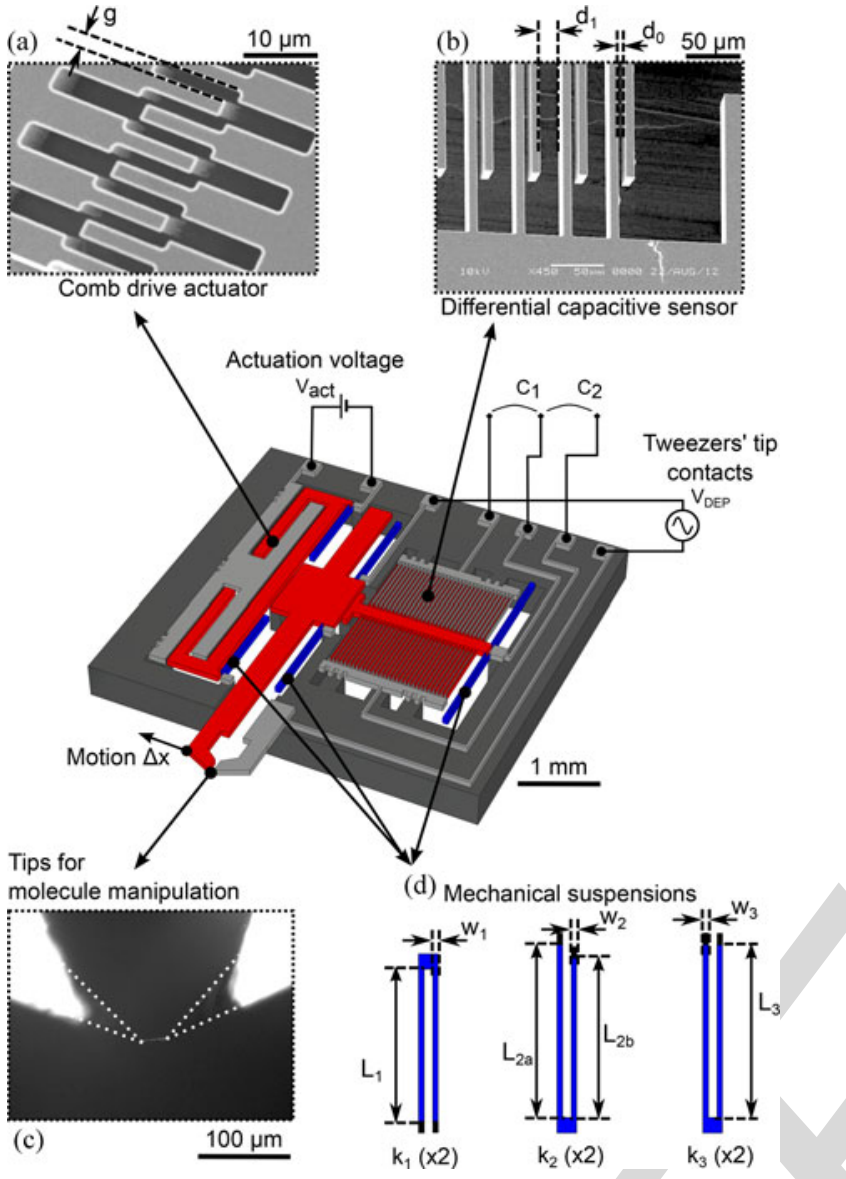

Fig. 1. SNT description. 3-D view of the device whose overall dimensions are $4.5 \times 4.5 \times 0.5 \mathrm{~mm}$. The mobile parts are shown in red and the mechanical suspensions in blue. (a) Scanning electronic microscopic (SEM) image of the actuator consisting of 880 pairs of interdigitated combs separated by a $2-\mu \mathrm{m}$ gap, and organized in two series. (b) SEM image of the integrated sensor of two opposing series of 30 combs. (c) Microscope image of the tweezers tips with a DNA bundle in between. (d) Design of the three sets of suspensions, $k_{1}$ for the actuator polarization, $k_{2}$ for the mobile arm, and $k_{3}$ for central sensor plate.

in MEMS design [22], [23]. The maximal stroke is limited compared to that achievable by a parallel plate actuator but the generated force only depends on the actuation voltage and not on the electrode position, thus, enabling a simpler actuation control. The force is given by (1) where $\varepsilon_{0}$ is the vacuum permittivity (we consider the relative permittivity of air $=1$ ), $N_{a}$ is the number of comb fingers, $t$ is the device thickness, $g$ is the lateral gap between fingers, and $V_{\text {act }}$ is the actuation voltage. Due to its capacitive structure, the comb drive generates attractive forces between its two electrodes

$$
F_{\mathrm{es}}=\frac{1}{2} \frac{\varepsilon_{0} \times N_{a} \times t}{g} V_{\mathrm{act}}^{2}=\alpha_{\mathrm{es}} \times V_{\mathrm{act}}^{2} .
$$

3) Mechanical Structure: The mobile part of the tweezers is linked to the silicon frame by flexible beams [see Fig. 1(d)]. Commonly integrated in mechanical microsystems [23], [24], folded beam springs are designed to minimize beam areas, decrease their mechanical stiffness and enhance displacement ranges [25]. In the SNT design of Fig. 1, three sets of folded beam suspensions support the mobile part of the system (the comb-drive actuator, the mobile tip, and the capacitive sensor) and provide the electrical connections for the actuation and the sensing. The springs are arranged symmetrically along the actuation and sensing axis to minimize any rotation, and their sum gives the total stiffness $k$ of the device.

A highly compliant system is required to sense the mechanical characteristic of trapped molecules on the tweezers response. On the other hand, a minimum stiffness is mandatory, 1) to endure the fabrication processes and manipulations, 2) to support the mobile system weight, and 3) to prevent sticking due to attractive surface forces between the comb-drive actuator and the capacitive sensor electrodes.

4) Displacement/Velocity Sensing: The tip position is measured by a capacitive sensor designed in a triplate configuration with transverse combs [see Fig. 1(b)] [26]. The central electrode, linked to the mobile arm, moves in between two fixed electrodes creating the two differential capacitances $C_{1}$ and $C_{2}$ whose difference, $\Delta C$, is related to the displacement $x$. For small displacements (i.e., $x$ is much smaller than the gaps between electrodes $d_{0}$ and $d_{1}$ ), $\Delta C$ is proportional to $x$ [17], $N_{b}$ is the number of capacitance electrodes, and $L$ the length of the electrodes

$$
\begin{aligned}
\Delta C & =C_{1}-C_{2} \\
& \simeq 2 \varepsilon_{0} N_{b} L t\left(\frac{1}{d_{0}^{2}}-\frac{1}{d_{1}^{2}}\right) x=\beta_{\mathrm{C}} \times x
\end{aligned}
$$

5) Electronic Read-Out: The tweezers motion is sensed by the measurement of the differential capacitance $\Delta C$ (2) through current sensing. In dynamic mode, a dc voltage $\left(V_{\text {polar }}\right)$ is applied on the mobile central electrode, whose motion generates dynamic currents $i_{1}$ and $i_{2}$ flowing through the capacitances $C_{1}$ and $C_{2}$, respectively, [27], [28]. The resulting currents related to the motion velocity are converted into voltages $V_{1}$ and $V_{2}$ by two low-noise current-to-voltage $(\mathrm{A} / \mathrm{V})$ preamplifiers (Signal Recovery, model 5182). The low input impedance of the preamplifier (virtual ground) ensures an accurate current conversion [17], [29]. attractive electrostatic forces generated in an interdigitated comb drive [see Fig. 1(a)], one of the most widely used architecture 
TABLE I

NUMERICAL VALUES OF DIMENSIONS AND PARAMETERS OF THE SNT

\begin{tabular}{lc}
\hline \hline Silicon thickness & \\
\hline$t(\mu \mathrm{m})$ & 30 \\
Comb drive actuator & \\
$N_{a}$ & 440 \\
$g(\mu \mathrm{m})$ & 2 \\
Mechanical suspensions & \\
$L_{1}, L_{2}$ a $(\mu \mathrm{m})$ & 900 \\
$L_{2 \mathrm{~b}}, L_{3}(\mu \mathrm{m})$ & 1000 \\
$w_{1}, w_{2}, w_{3}(\mu \mathrm{m})$ & 15 \\
Capacitive sensor & \\
$N_{b}$ & 30 \\
$L(\mu \mathrm{m})$ & 585 \\
$d_{0}(\mu \mathrm{m})$ & 5 \\
$d_{1}(\mu \mathrm{m})$ & 20 \\
\hline
\end{tabular}

The device dimensions are defined in Fig. 1.

Finally, in harmonic mode, when the tweezers is moved by a sinusoidal actuation, a lock-in amplifier (NF, model LI 5640) performs the low-noise detection of the differential signal (amplitude and phase of $V_{1}-V_{2}$ ) at the actuation frequency. The reference signal is the motion frequency imposed by the actuation voltage.

All dimensions and parameters that has been considered for a proper model of the SNT are summed up in the TableI. Furthermore, Young's modulus and the density of the silicon are, respectively, $165 \mathrm{GPa}$ and $2329 \mathrm{~kg} \cdot \mathrm{m}^{-3}$, and the permittivity $\varepsilon_{0}$ is $8.85 \times 10^{-12} \mathrm{~kg}^{-1} \cdot \mathrm{m}^{-3} \cdot \mathrm{A}^{2} \cdot \mathrm{s}^{4}$.

\section{B. Monitoring Biomolecules Manipulation With SNT}

This Section presents the way that the SNT are used as biosensors and points out the measurement sensitivity requirements. This example is illustrated with DNA but the same technique has been applied to gelatin [30] and microtubules [31].

1) DNA Bundle Trapping by DEP: The trapping is achieved by applying an ac electric field $\left(E=1 \mathrm{MV} \cdot \mathrm{m}^{-1}\right)$ between the two opposing tips of the tweezers [32] once partially immersed in the solution. The retrieving of the DNA bundle is routinely performed from a droplet solution [15], [17], and single molecule trapping has even been demonstrated with a pulsed DEP signal [16].

In [20], an improved method is proposed in which the tips are introduced into an open fluidic cavity optimized to guaranty a stable meniscus. The SNT position is fixed and the cavity is mounted on a $X Y Z$ stage controlled by programmable robot for repeatable and controlled tip immersion, as illustrated in Fig. 2(a)-(c).

2) Real-Time Monitoring: The SNT characterization allows monitoring of the DNA trapping in real time. The characterization of the SNT in real time allows the monitoring of the DNA trapping. The number of trapped DNA molecules during the DEP is controlled by the evolution of the resonance frequency and quality factor of the system (Tweezers+DNA bundle). The SNT are modeled by a linear second-order model as depicted in Fig. 2(d). The resonance frequency, $f_{\mathrm{R}}$, and the quality factor
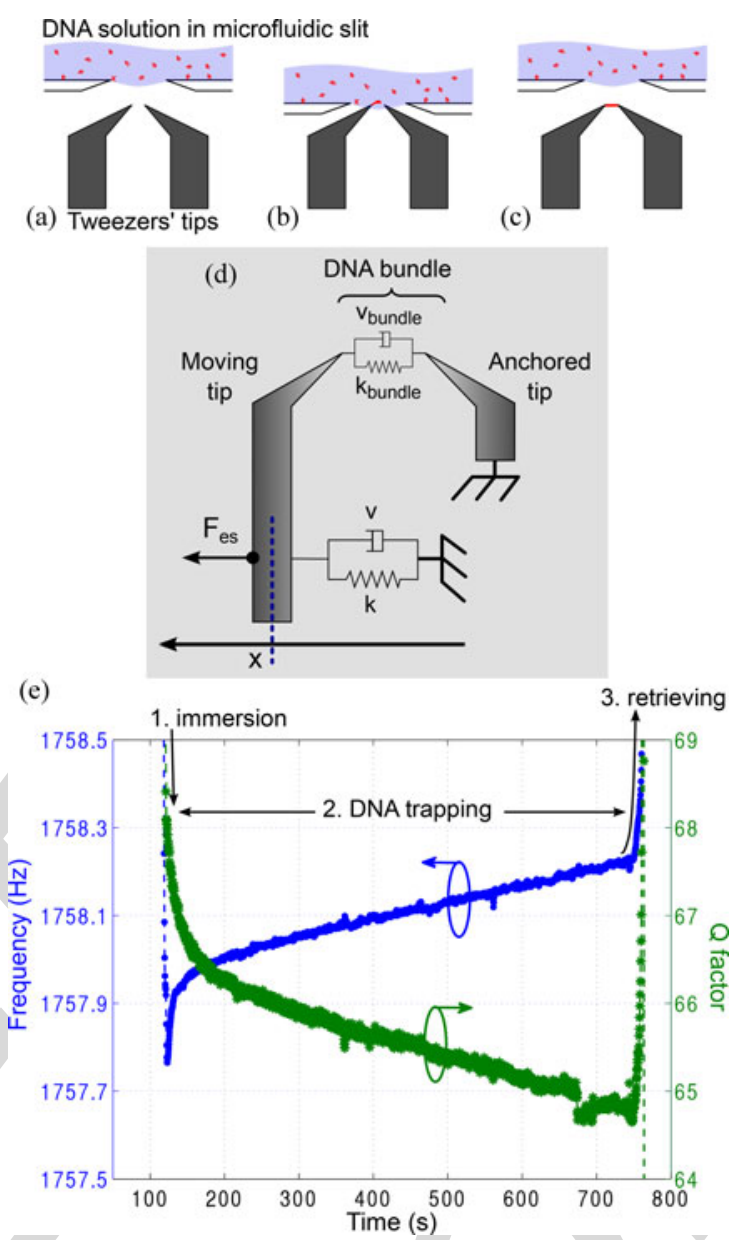

Fig. 2. $\lambda$-DNA molecules trapping with SNT. The first three sketches illustrate the key phases of the experiment: (a) the immersion of the tips in the DNA solution, (b) the DNA trapping by DEP, and (c) the retrieving of DNA bundle between the tips. (d) Equivalent dynamic model of the SNT with bundle. (e) Evolution of the $S N T+$ bundle resonance frequency and $Q$ factor during the trapping.

$Q$ of the $S N T+$ bundle damped oscillator are defined by

$$
\begin{aligned}
f_{\mathrm{R}}(t) & =\frac{1}{2 \pi} \sqrt{\frac{\left(k+k_{\text {bundle }}(t)\right)}{M}} \\
Q(t) & =\frac{\sqrt{\left(k+k_{\text {bundle }}(t)\right) \times M}}{\left(\nu+\nu_{\text {bundle }}(t)\right)}
\end{aligned}
$$

where $M$ is the mass of the movable tip, $k$ is the stiffness of the suspensions, and $\nu$ is the equivalent viscous losses. $k_{\text {bundle }}$ and $\nu_{\text {bundle }}$ are the time varying bundle stiffness and viscosity; the mass of the bundle is neglected compared to $M$.

As shown in Fig. 2(e), as the DEP trapping progresses, the system moves to higher resonance frequencies indicating an increase in the bundle stiffness according to (4). At the same time, the signal amplitude at resonance, proportional to the quality factor $Q$, is decreasing, revealing higher viscous losses $\nu_{\text {bundle }}$ as the bundle forms, in accordance with (5).

In this experiment, the resonance frequency experiences a 193 shift of $0.4 \mathrm{~Hz}$ that corresponds to an increase in the stiffness of 194 $12 \mathrm{mN} \cdot \mathrm{m}^{-1}$, i.e., a bundle containing $\sim 200 \lambda$-DNA molecules 
4 and
[19]. (For the sake of clarity, it should be noted that the SNT used in this trapping experiment has different characteristics than those used in the feedback approach of Sections III and IV)

3) Sensor Resolution: Accurate biosensing by SNT requires high-resolution measurements. Thus, special care in signal conditioning (detection of small currents $<10 \mathrm{pA}$ ), noise reduction, and control of the experimental conditions (e.g., the stability of the meniscus air/biological liquid/tweezers) have allowed to sense resonance frequency shifts of $25 \mathrm{mHz}$ and quality factor changes of 0.2. Based on this resolution, the minimum change that can be sensed due to the stiffness variation is in the range of 15 molecules of $\lambda$-DNA [20].

After trapping, the bundle of molecules is mechanically stimulated (in air or in a biological solution) with a sinusoidal signal at the resonance frequency of the system. Slight changes in the frequency response permit a fine characterization of the evolution of the mechanical properties of the molecule bundle revealing biological interactions.

\section{DynAmic Modeling AND IMPROVEMENT OF THE PARAMETRIC SENSITIVITY By A FEEDBACK APPROACH}

In this Section, we describe how to reduce the closed-loop resonance frequency of the tweezers in order to improve its sensitivity to molecule stiffness variations.

\section{A. Dynamic Modeling and Open-Loop Sensitivity to Stiffness Variations}

1) Modeling: Newton's second law applied to the damped oscillator formed by the $S N T+$ bundle of Fig. 2(d) can be formulated by

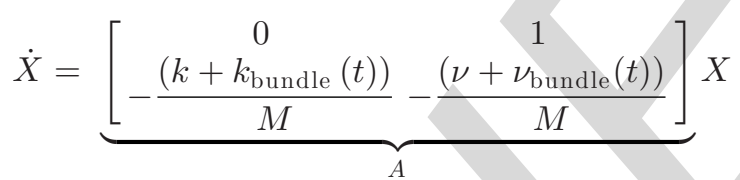$$
+\underbrace{\left[\begin{array}{c}
0 \\
\frac{1}{M}
\end{array}\right]}_{B} F_{\mathrm{es}}
$$

$$
y=\underbrace{\left[\begin{array}{ll}
0 & 1
\end{array}\right]}_{C} X
$$

where $A \in \mathbb{R}^{2}, B \in \mathbb{R}^{(2,1)}, C \in \mathbb{R}^{(1,2)}, X$ is the state vector (displacement \& velocity, $X=\left(\begin{array}{l}x \\ \dot{x}\end{array}\right)$ ), and $y$ is the output vector or the measurement.

2) Identification: Prior to the development of an accurate control strategy, the model parameters $[M, k, v$, actuation, and sensor gains of (1)-(5)] need to be extracted from device measurements. These parameters are identified through standard recursive approach with least squares method from SNT responses to small signal actuation with a $20 \mathrm{~V}$ offset. Identified parameters are summarized in Table II.
TABLE II

THEORETICAL AND IDENTIFIED MODEL PARAMETER VALUES OF THE SNT

\begin{tabular}{lcc}
\hline \hline Parameters & Theoretical & Identified \\
\hline $\begin{array}{l}\text { Mechanical parameters } \\
\mathrm{M}(\mathrm{kg})\end{array}$ & $360 \times 10^{-9}$ & $360 \times 10^{-9}$ \\
$\mathrm{k}\left(\mathrm{N} \cdot \mathrm{m}^{-1}\right)$ & $49.3^{a}$ & 24.9 \\
$\nu\left(\mathrm{Ns} \cdot \mathrm{m}^{-1}\right)$ & - & $100 \times 10^{-6}$ \\
Comb-drive actuator & $29.2 \times 10^{-9 a}$ & $35.5 \times 10^{-9}$ \\
$\alpha_{\mathrm{es}}\left(\mathrm{N} \cdot \mathrm{V}^{-2}\right)$ & $412.2 \times 10^{-9 a}$ & $227.5 \times 10^{-9}$ \\
Capacitive sensor & $\beta_{\mathrm{C}}\left(\mathrm{F} \cdot \mathrm{m}^{-1}\right)$ & \\
\hline \hline
\end{tabular}

${ }^{a}$ These values are calculated from the designed springs and electrodes widths and does not take into account the significant beam narrowing during etching processes.

3) Open-Loop Sensitivity to Stiffness Variation: The mini- 235 mum number of molecules that can be discerned by resonance 236 frequency shifts due to the molecular stiffness variation is linked 237 to the SNT sensitivity to stiffness variation $\Delta k$, i.e.,

$$
\frac{\partial f_{\mathrm{R}}}{\partial k}=\frac{1}{4 \pi \sqrt{k M}} \text { or } \frac{1}{8 \pi^{2} M f_{\mathrm{R}}} .
$$

This sensitivity is equal to $26.4 \mathrm{~Hz} /\left(\mathrm{N} \cdot \mathrm{m}^{-1}\right)$ with the iden- 239 tified parameters of Table II. It appears that for a given molecu- 240 lar stiffness change, $\Delta k$, the effect on the resonance frequency 241 variation $\Delta f_{\mathrm{R}}$ is enhanced with low SNT stiffness, $k$, and, there- 242 fore, for low resonance frequency $f_{\mathrm{R}}$. In relation to Fig. 2, the 243 current experimental resolution in the resonant frequency shift 244 measurement is close to $25 \mathrm{mHz}$, a value that corresponds to 245 $1 \mathrm{mN} \cdot \mathrm{m}^{-1}$ or $15 \lambda$-DNA molecules. From (8), a reduction of 246 $f_{\mathrm{R}}$ by one order of magnitude; i.e. 2 orders of magnitude for 247 $k$, would improve the detection threshold down to the single molecule level.

The development of a new MEMS device having a very low stiffness $\left(<0.2 \mathrm{~N} \cdot \mathrm{m}^{-1}\right.$ remains extremely challenging in terms of fabrication and operation. Thus, we propose to reduce the overall stiffness by closed-loop control. In such a control strategy, the physical system (i.e., the SNT) remains the same but the closed-loop system SNT combined with the feedback law will have the desired designed dynamic behavior.

\section{B. Improvement of the Parametric Sensitivity by a Feedback Approach}

1) Control Strategy: The control design strategy is depicted 259 in the flowchart of Fig. 3. The aim of the feedback is to reduce the 260 resonance frequency of the closed-loop system. To this end, we 261 use a state feedback eigenstructure assignment in order to assign 262 both the closed-loop resonance frequency and damping factor. 263 This state feedback is then implemented using a Luenberger- 264 kind observer. The originality of the observer we use is that it 265 has to be designed in order to neither deteriorate the closed-loop 266 sensitivity nor amplify the noise.

2) Eigenstructure Assignment Using State Feedback: The 268 system is under its controllable canonical state-space represen- 269 tation $(A, B, C)$ given by (6) and (7). The state feedback gain 270 vector $L=\left(l_{1}, l_{2}\right) \in \mathbb{R}^{(1,2)}$ is designed to assign the desired 271 


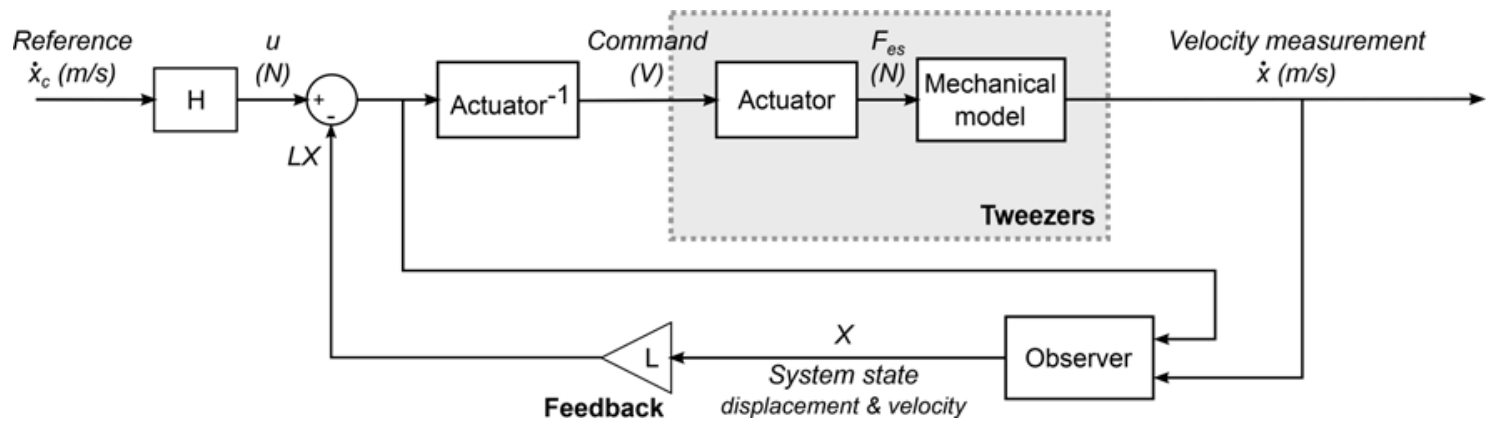

Fig. 3. Feedback control scheme. Gray box, called Tweezers, comprises the mechanical and the actuator models. Actuator square law needs to be inverted in order to linearize the control signal. The state feedback gain vector $L$ and the feedforward gain $H$ are designed to assign the desired closed-loop poles and to ensure unitary static gain. The observer is a Luenberger observer reconstructing the state of the system $X$ for the state feedback. The sensor model is not shown here. The device output voltage is converted into the tip velocity by dividing by the sensor gain $1 / \beta_{C}$.

TABLE III

Pole Placement of the Closed-Loop System and State Feedback Gain $L$ ACCORDING TO THE RESONANCE FREQUENCY REDUCTION $n$.

\begin{tabular}{lcc}
\hline \hline Freq. & $L\left(\left[\mathrm{~N} \cdot \mathrm{m}^{-1}\right],\left[{\left.\left.\mathrm{Ns} \cdot \mathrm{m}^{-1}\right]\right)}^{\text {Poles }}\right.\right.$ \\
\hline$f_{\mathrm{R}}$ & $(0,0)$ & $-138.9 \pm 8.3 \times 10^{3} i$ \\
$f_{\mathrm{R}} / 1.2$ & $\left(-7.6,-16.7 \times 10^{-6}\right)$ & $-115.7 \pm 6.9 \times 10^{3} i$ \\
$f_{\mathrm{R}} / 2.0$ & $\left(-18.7,-50.0 \times 10^{-6}\right)$ & $-69.4 \pm 4.2 \times 10^{3} i$ \\
$f_{\mathrm{R}} / 3.2$ & $\left(-22.5,-68.8 \times 10^{-6}\right)$ & $-43.4 \pm 2.6 \times 10^{3} i$ \\
$f_{\mathrm{R}} / 5.0$ & $\left(-23.9,-80.0 \times 10^{-6}\right)$ & $-27.8 \pm 1.7 \times 10^{3} i$ \\
$f_{\mathrm{R}} / 10$ & $\left(-24.7,-90.0 \times 10^{-6}\right)$ & $-13.9 \pm 0.8 \times 10^{3} i$ \\
\hline \hline
\end{tabular}

closed-loop poles. The actuation of the system $F_{\mathrm{es}}$ is equal to $u-L X$, and the closed-loop system model becomes

$$
\dot{X}=\left[\begin{array}{cc}
0 & 1 \\
-\frac{k+l_{1}}{M} & -\frac{\nu+l_{2}}{M}
\end{array}\right] X+\left[\begin{array}{c}
0 \\
\frac{1}{M}
\end{array}\right] u \text {. }
$$

Thus, the closed-loop resonance frequency and sensitivity are given by

$$
\begin{aligned}
f_{\mathrm{R}-\mathrm{cl}} & =\frac{1}{2 \pi} \sqrt{\frac{\left(k+l_{1}\right)}{M}} \\
\frac{\partial f_{\mathrm{R}-\mathrm{cl}}}{\partial k} & =\frac{1}{4 \pi \sqrt{\left(k+l_{1}\right) M}}=\frac{1}{8 \pi^{2} M f_{\mathrm{R}-\mathrm{cl}}} .
\end{aligned}
$$

The state feedback gain $L$ is, then, determined in order to assign the closed-loop poles in such a way that the system resonates at a lower frequency than the natural frequency of the tweezers (see Table III). $L$ is computed to scale down this resonant frequency (initially $1323.6 \mathrm{~Hz}$ ), by a given factor depending on the desired sensitivity enhancement while keeping the damping factor unchanged.

When the closed-loop resonance frequency is scaled down by a factor $n$ compared to the SNT natural resonance frequency, the sensitivity to small stiffness variation is improved with the same ratio according to (11). Fig. 4 shows the computed frequency shift of the closed-loop system caused by a significant stiffness variation for different frequency scaling down factor, $n$.

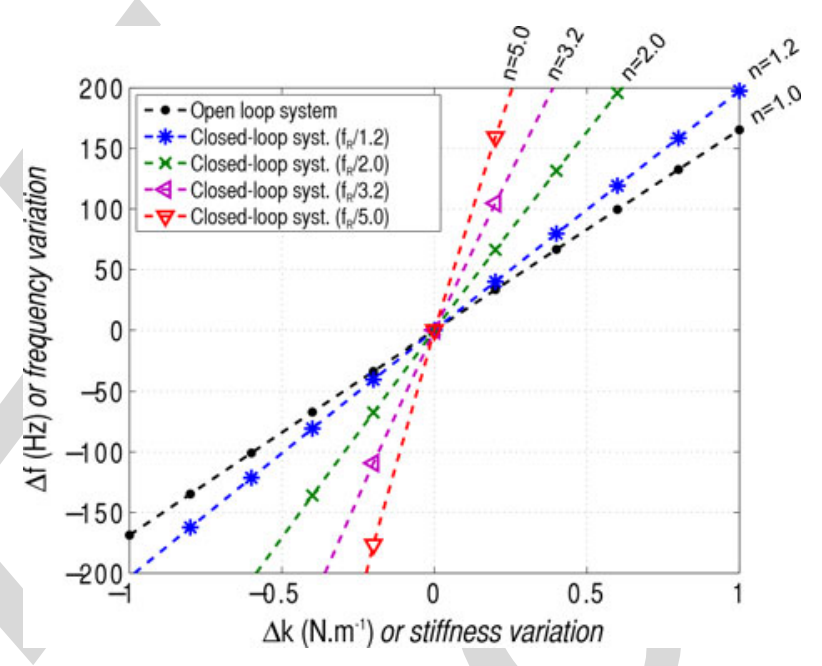

Fig. 4. Evolution of the resonance frequency shift $\Delta f_{\mathrm{R}}$ and $\Delta f_{\mathrm{R}-\mathrm{cl}}$ with the added stiffness $\Delta k$ variation for different frequency reduction ratio $n$.

\section{Observer Design}

The implementation of the aforementioned state feedback is done through the use of a Luenberger observer. The observer is designed such that it preserves the good closed-loop sensitivity to parametric variations and it does not amplify too much noise.

The poles of the observer have then to be carefully chosen. We used the following guidelines.

(1) The observer is designed to be faster than the original device - with poles at least two times faster than the poles of the system in open loop (cf., Table III).

(2) The observer poles are chosen not too fast in order to avoid excessive noise amplification.

(3) The final location of the observer poles is chosen in order to preserve the sensitivity of the system to stiffness variations (by using root locus).

In the following section, simulations illustrate 1) the relevance of the method and 2) the importance of the design of the observer towards the enhancement of the sensitivity. 


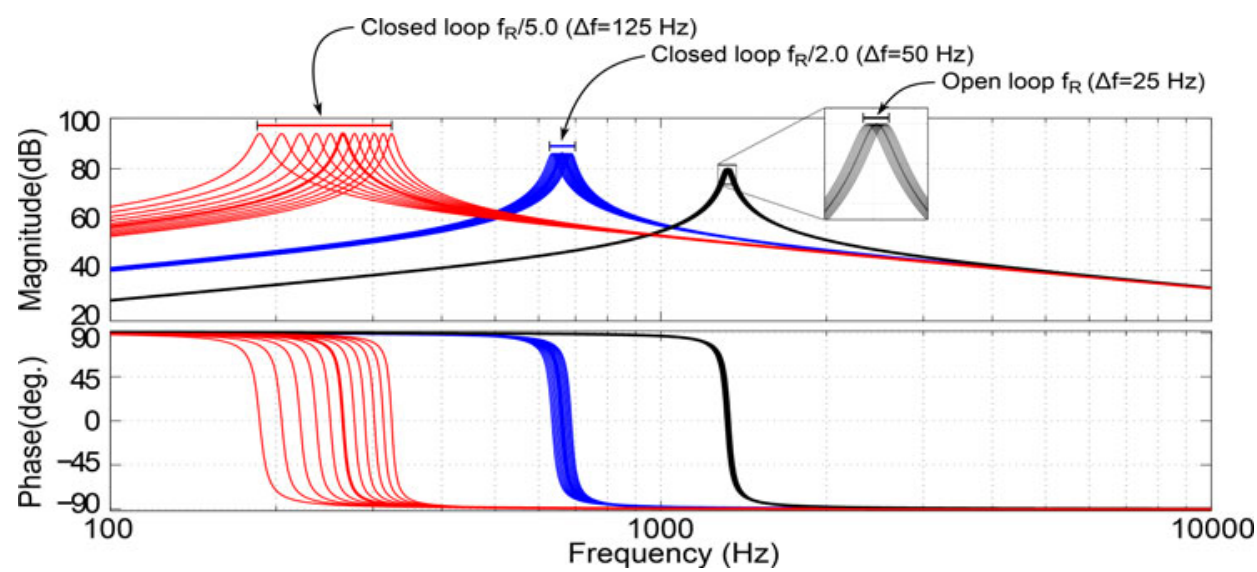

Fig. 5. Simulated frequency results for open-loop driven system and two different closed-loop systems. The three systems undergo a variation of $k$ the system stiffness. $k$ vary from -0.5 to $0.5 \mathrm{~N} / \mathrm{m}$ by $0.1 \mathrm{~N} / \mathrm{m}$ step. In black line, the tweezer transfer function, i.e., the open-loop system. In blue line, the implemented $(n=2)$ closed-loop system transfer function. The system resonates at a frequency twice lower. In red line, the implemented $(n=5)$ closed-loop system transfer function. The system resonates at a frequency five times lower.

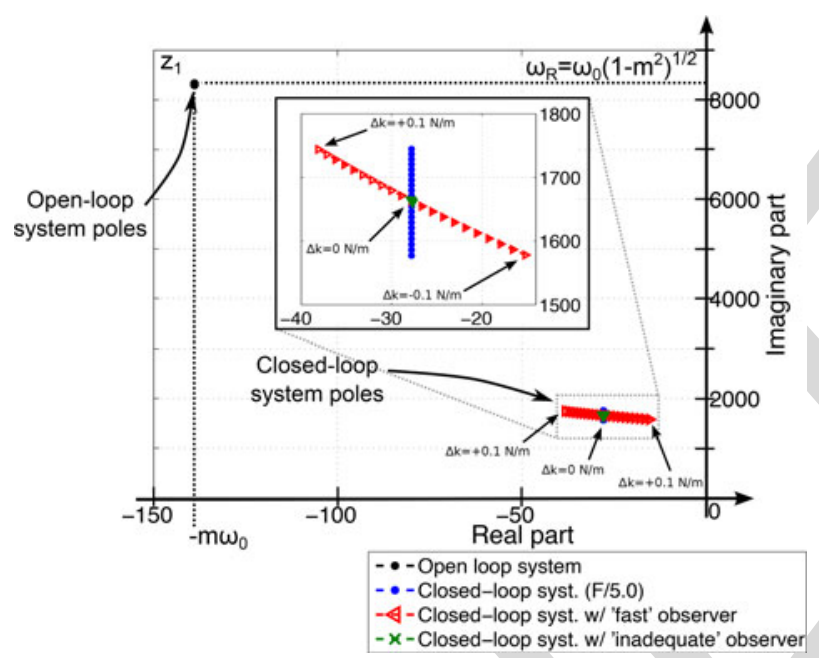

Fig. 6. Root locus of the closed-loop systems with $n=5$ and with different observers. Complex conjugate poles are plotted in the positive imaginary half $s$ plan. The parameter $k$ varies from -0.1 to $0.1 \mathrm{~N} / \mathrm{m}$ by $0.01 \mathrm{~N} / \mathrm{m}$ steps. The black dots show the poles of the open-loop driven system. The ideal pole path of the closed-loop system due to the $k$ variations are plotted with blue dots (i.e., no observer). For different observers designs, poles dependencies (and equivalent resonance frequency $\omega_{\mathrm{R}}=2 \pi f_{\mathrm{R}}$ and damping $m$ ) on the tweezers stiffness $k$ are shown by red triangle and green cross plots. NB: Green cross dots path are imperceptible since they are at this scale all concentrate in the middle.

\section{Simulation Results}

From parameters identified in Table II, the feedback scheme (see Fig. 3) has been first programmed and tested under MATLAB/Simulink without implementing the observer (i.e., all the state variables are supposed to be measured). Fig. 5 compares the resonance frequency shift between the open-loop driven system and the closed-loop systems computed for two resonance frequency reduction factors set to $n=2$ and 5 . As expected, the sensitivity of the closed-loop system is improved proportionally to $n$.

In a second instance, we implemented two different kinds of observers (with different dynamics); Fig. 6 illustrates two cases.
TABLE IV

POLE Placement OF the ObSERVER FOR STATE FEedback IMPLEMENTATION

\begin{tabular}{lc}
\hline \hline Open-loop system (Tweezers) & $z_{1,2}=-138.9 \pm 8.3 \times 10^{3} i$ \\
\hline closed-loop system $(n=5)$ & $z_{1,2}=-27.8 \pm 1.7 \times 10^{3} i$ \\
Observer 1 (fast) & $z_{1,2}=-277.8 \pm 0.2 \times 10^{3} i$ \\
Observer 2 (slow) & $z_{1,2}=-27.8 \pm 0.2 \times 10^{3} i$ \\
Observer 3 (inadequate) & $z_{1,2}=-277.8 \pm 16.7 \times 10^{3} i$ \\
\hline \hline
\end{tabular}

This Figure shows that the root locus (due to $k$ parameter varia- 320 tions) is deformed by the observer dynamics. The sensitivity of 321 the resonance frequency to stiffness variations is given by the 322 amplitude of the imaginary axis variations. Table IV reports the 323 poles of the observers for which simulation results are presented. 324

In the insert of Fig. 6, the poles of the system implemented 325 with the observer named inadequate do not move compared to 326 the ideal root locus (ideal state feedback case). If the poles of 327 the observer are inappropriately chosen, the sensitivity of the 328 poles to variations of $k$ is significantly reduced. Observer poles 329 close to the real axis, i.e., with an imaginary part close to 0,330 are the more appropriate to reconstruct the displacement state 331 and to preserve the sensitivity of the system to variations of $k$. 332 The socalled fast observer allows us to increase the resonance 333 frequency shift ( $\omega_{\mathrm{R}}=2 \pi f_{\mathrm{R}}$ in Fig. 6 ) close to the performances 334 theoretically expected.

\section{EXPERIMENTAL APPLICATION FOR EXTRA-STIFFNESS CHARACTERIZATION}

The previous method has been experimentally tested with the 338 mechanical characterization of biomolecules of fibronectin. The 339 physical sensor is the SNT, while the feedback controller and 340 the observer are implemented in a dSPACE prototyping board. 341

\section{A. Experimental Protocol}

Fibronectin is a protein, $100 \mathrm{~nm}$ in length, of the extracel- 343 lular matrix which plays a major role in cell adhesion, growth, 344 


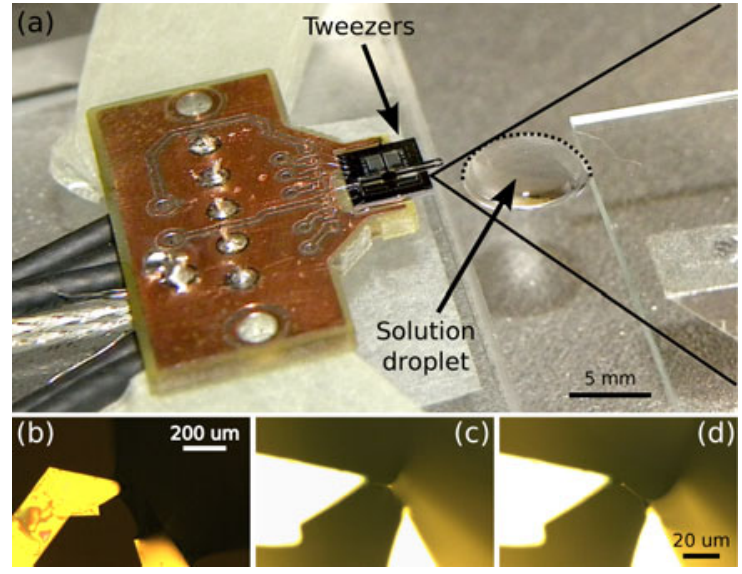

Fig. 7. Experimental setup for the trapping of fibronectin molecules. (a) The SNT are fixed. A droplet of fibronectin solution is dropped on a glass slice which is mounted on the XYZ stage. (b)-(d) Sequences of the molecule combing. Under optical microscopy, the tweezers' tips are retrieved from the solution meniscus. A bundle of fibronectin is released between the tips.

migration, and differentiation [33]. These molecules are used to polymerize the fibrillar matrix at the surface of the cell. We have used this property to trap by combing a bundle of fibronectin. After immersion of the tips in the solution, they are retrieved by the side forming a polymerized bundle of molecules (see Fig. 7).

The closed-loop systems are evaluated with fibronectin bundle in air, in dry condition. This stable condition was preferred to the immersed one as we can avoid any effect of liquid surface tension stability that can interfere with the sole system response. For each case, a sinusoidal reference of $0.02 \mathrm{~V}_{\mathrm{AC}}$ with an offset of $20 \mathrm{~V}_{\mathrm{DC}}$ is applied to the system and the oscillation frequencies are spanned from 1000 to $2000 \mathrm{~Hz}$ with a step of $2 \mathrm{~Hz}$. Then, the measurement is performed with the lock-in amplifier.

Two sets of experiments have been performed with two different bundles. From the resonance frequency shifts in open loop, the stiffness of the first bundle is $11.8 \mathrm{~N} \cdot \mathrm{m}^{-1}$, and $4.3 \mathrm{~N} \cdot \mathrm{m}^{-1}$ for the second one. In total, 22 resonance responses are recorded and compared.

\section{B. Results and Discussions}

1) Experimental Results: Fig. 8 shows the frequency responses of four different systems with and without a bundle of fibronectin.

In Fig. 8(a), the responses of the open-loop driven SNT are given. The dashed-line curve is the reference curve, which corresponds to the frequency response of the SNT alone driven in open loop. The solid line is the response of the tweezers with the bundle trapped in between the tips. The resonance frequency increases and the amplitude decreases due to the additional stiffness and loss contributions of the molecules. In Fig. 8(b)-(d), the results of the closed-loop systems with desired reduction ratios are of 1.1, 1.2 and 1.5.

Resonance responses are fitted with a second-order resonator model and characteristics such as the resonance frequency are extracted. The Table V sums up the resonance frequencies for the experiment with/without the first bundle for five different
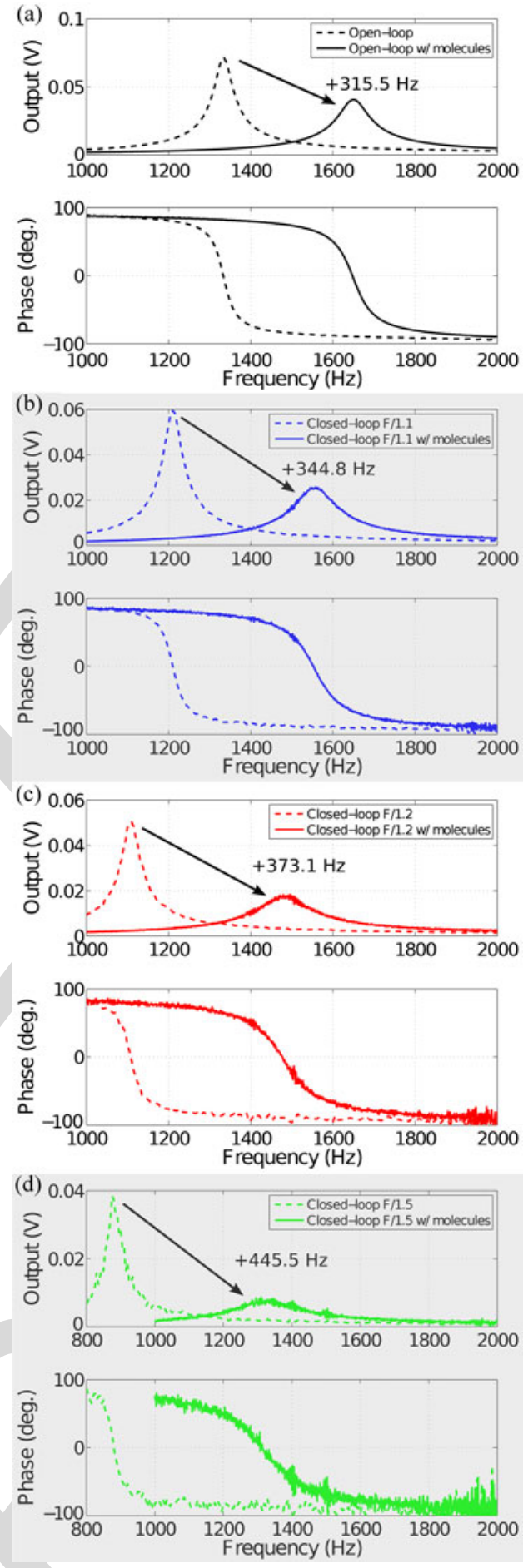

Fig. 8. Frequency responses of different implemented closed-loop systems for $0.02 \mathrm{~V}$ sinusoidal signal with an offset of $20 \mathrm{~V}$. In dotted lines, the responses of the systems with the bundle of molecules. In plain lines, the responses of the systems without molecules. (a) Open-loop driven systems. (b) Closed-loop systems implemented with $f_{\mathrm{R}} / 1.1$. (c) Closed-loop systems implemented with $f_{\mathrm{R}} / 1.2$. (d) Closed-loop systems with $f_{\mathrm{R}} / 1.5$.

systems. Through reducing the resonance frequency of the sys- 380 tem, the measured results prove the increase of the frequency 381 shift due to the extra-stiffness of the bundle. 382

Moreover Fig. 9 tends to 1) confirm with second set of exper- 383 iments, the enhancement of the sensitivity through the proposed 384 
TABLE V

EXPERIMENTAL RESUlTS FOR THE BUNDLE 1 (RELATED TO FIG. 8)

\begin{tabular}{lccc}
\hline \hline System $(n)$ & $\begin{array}{c}\text { Freq. } \\
\text { w/o bundle }(\mathrm{Hz})\end{array}$ & $\begin{array}{c}\text { Freq. } \\
\text { w/ bundle }(\mathrm{Hz})\end{array}$ & $\begin{array}{c}\text { Freq. shift } \\
(\mathrm{Hz})\end{array}$ \\
\hline Open loop (1.0) & 1333.6 & 1649.1 & +315.5 \\
Closed-loop (1.1) & 1211.1 & 1555.9 & +344.8 \\
Closed-loop (1.2) & 1109.1 & 1482.2 & +373.1 \\
Closed-loop (1.5) & 881.9 & 1327.4 & +445.5 \\
Closed-loop (2.0) & 653.9 & 1175.6 & +521.7 \\
\hline \hline
\end{tabular}

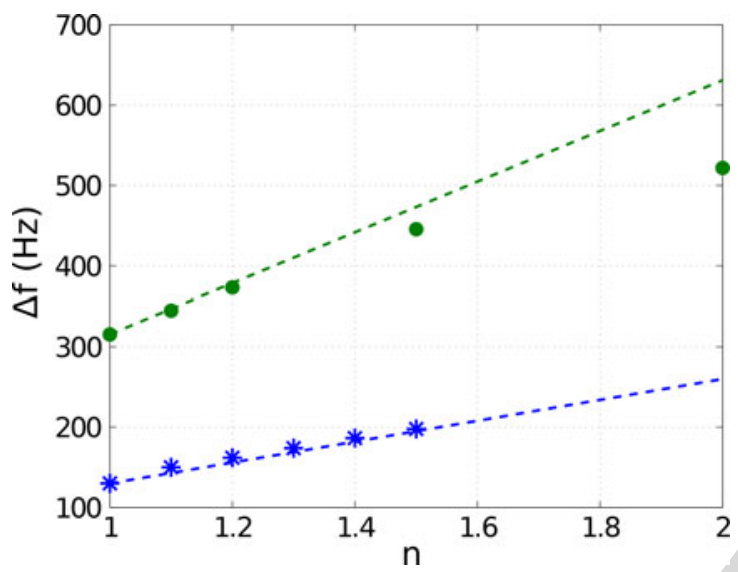

Fig. 9. Synthesis of the experimental results. In abscissa, is informed the reduction factor $(n)$ applied to the resonance frequency for the closed-loop system. The shift $\Delta f$ is the resonance frequency difference due to the presence of the bundle of molecules in between the tips. The dotted lines represent the theoretical improvement expected. The two sets of results obtained with two different bundles are plotted. The green dots correspond to the experiment of Fig 8 and TableV (bundle of $11.8 \mathrm{~N} \cdot \mathrm{m}^{-1}$ stiffness). The blue stars corresponds to the second bundle of $4.3 \mathrm{~N} \cdot \mathrm{m}^{-1}$ stiffness. feedback strategy and 2) show a good agreement with the theory. Small differences are discussed in the following section.

2) Discussion: The synthesis of Fig. 9 demonstrates the enhancement of the frequency shifts in agreement with the theory. However, the enhancement for closed-loop system with a reduction factor of 2.0 is lower than expected, and the implementation for a higher reduction factor has not been achieved. In this case, the system tends to become unstable. We mainly associated this phenomenon to the observer implementation and to the presence of some delays in the feedback loop.

We have demonstrated previously that observer's dynamic changes the root locus of system's poles, the behavior of the closed-loop system under parameter variations and impacts the performances of the method. Furthermore, delays have been characterized due to D/A and A/D converters dead times and to the phase shift brought by the current amplifiers. Current works are devoted to the precise characterization of such delays and to their integration in the control design process.

\section{CONCLUSION AND Future WORK}

The present study investigates the relevance of a feedback approach in the improvement of the performances of MEMS tweezers for the detection and the mechanical characterization of biological molecules. An improvement of $50 \%$ on the sensitivity to mechanical stiffness variations has been reached theoretically and experimentally on fibronectin bundles through the emulation of a more compliant system. The stiffness have been brought down to $10.5 \mathrm{~N} / \mathrm{m}$ instead of originally $24.5 \mathrm{~N} / \mathrm{m}$.

The main drawback of this approach is the sensitivity of 412 the observer to the stiffness variations. Unusually, the poles of 413 the observer are uncontrollable resulting from the separation 414 principle. During the sensing of the molecules stiffness, the 415 separation principle is not satisfied anymore and the observer 416 scheduled observers aiming at adapting the observer dynamics 418 with respect to sensed parametric variations. It should solve the 419 main drawback of this promising approach and allows us to go 420 one step further into the theoretical closed-loop performances.

\section{ACKNOWLEDGMENT}

The authors would like to thank A. W. Coleman from the University of Lyon, Lyon, France, for the discussion and proofreading of the text. The photolithography masks were fabricated with the 8-inch EB writer F5112+VD01 donated by Advantest Corporation to the VLSI Design and Education Center (the University of Tokyo).

\section{REFERENCES}

[1] C. Bustamante, J. Marko, E. Siggia, and S. Smith, "Entropic elasticity of lambda-phage DNA," Science, vol. 265, no. 5178, pp. 1599-1600, 1994.

[2] P. Cluzel, A. Lebrun, C. Heller, R. Lavery, J. L. Viovy, D. Chatenay, and F. Caron, "DNA: An extensible molecule," Science, vol. 271, no. 5250 , pp. 792-794, Feb. 1996.

[3] G. Bao, "Mechanics of biomolecules," J. Mech. Phys. Solids, vol. 50, no 11 , pp. 2237-2274, 2002.

[4] A. Bancaud, N. Conde E Silva, M. Barbi, G. Wagner, J.-F. Allemand, J. Mozziconacci, C. Lavelle, V. Croquette, J.-M. Victor, A. Prunell, and J.-L. Viovy, "Structural plasticity of single chromatin fibers revealed by torsional manipulation," Nat. Struct Mol. Biol., vol. 13, no. 5, pp. 444-450, May. 2006.

[5] J. Gore, Z. Bryant, M. D. Stone, M. Nöllmann, N. R. Cozzarelli, and C. Bustamante, "Mechanochemical analysis of DNA gyrase using rotor bead tracking," Nature, vol. 439, no. 7072, pp. 100-104, Jan. 2006.

[6] O. Chaudhuri, S. H. Parekh, and D. A. Fletcher, "Reversible stress softening of actin networks," Nature, vol. 445, no. 7125, pp. 295-298, Jan. 2007.

[7] T. Hawkins, M. Mirigian, M. S. Yasar, and J. L. Ross, "Mechanics of microtubules," J. Biomech., vol. 43, no. 1, pp. 23-30, Jan. 2010.

[8] F. Amblard, B. Yurke, A. Pargellis, and S. Leibler, "A magnetic manipulator for studying local rheology and micromechanical properties of biological systems," Rev. Sci. Instrum., vol. 67, no. 3, pp. 818-827, 1996.

[9] C. Gosse and V. Croquette, "Magnetic tweezers: Micromanipulation and force measurement at the molecular level," Biophys. J., vol. 82, no. 6, pp. 3314-3329, 2002. R. Simmons, J. Finer, S. Chu, and J. Spudich, "Quantitative measurements 456 of force and displacement using an optical trap," Biophys. J., vol. 70, 457 no. 4, pp. 1813-1822, 1996.

[11] E. L. Florin, V. T. Moy, and H. E Gaub, "Adhesion forces between individual ligand-receptor pairs," Science, vol. 264, no. 5157, pp. 415- 460 417, Apr. 1994

[12] A. Ishijima, T. Doi, K. Sakurada, and T. Yanagida, "Sub-piconewton force fluctuations of actomyosin in vitro," Nature, vol. 352, pp. 301-306, 1991.

[13] F. Beyeler, A. Neild, S. Oberti, D. Bell, Y. Sun, J. Dual, and B. Nelson, "Monolithically fabricated microgripper with integrated force sensor for manipulating microobjects and biological cells aligned in an ultrasonic field," J. Microelectromech. Syst., vol. 16, no. 1, pp. 7-15, 2007. manipulation of biological cells using a monolithic MEMS microgripper with two-axis force feedback," J. Micromech. Microeng., vol. 18, no. 5, p. 055013, Apr. 2008.

[15] G. Hashiguchi, T. Goda, M. Hosogi, K. Hirano, N. Kaji, Y. Baba, K. Kakushima, and H. Fujita, "DNA manipulation and retrieval from 466 poles can become unstable. We are actually working on self- 417

\section{9} . ,

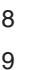

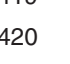
at 422 423 424 425 426 427 428 430 431 432 433 434 435 436 437
438 439 440 55
56 57 59
60 461 462 463 464 465 467 468 469 473 
an aqueous solution with micromachined nanotweezers," Anal. Chem., vol. 75 , no. 17 , pp. $4347-4350,2003$

[16] M. Kumemura, D. Collard, N. Sakaki, C. Yamahata, M. Hosogi, G. Hashiguchi, and H. Fujita, "Single-DNA-molecule trapping with silicon nanotweezers using pulsed dielectrophoresis," J. Micromech. Microeng., vol. 21, p. 054020, 2011.

[17] C. Yamahata, D. Collard, B. Legrand, T. Takekawa, M. Kumemura, G. Hashiguchi, and H. Fujita, "Silicon nanotweezers with subnanometer resolution for the micromanipulation of biomolecules," J. Microelectromech. Syst., vol. 17, no. 3, pp. 623-631, 2008

[18] M. Kumemura, D. Collard, S. Yoshizawa, D. Fourmy, N. Lafitte, L. Jalabert, S. Takeuchi, T. Fujii, and H. Fujita, "Direct bio-mechanical sensing of enzymatic reaction on DNA by silicon nanotweezers," in Proc. IEEE 23rd Int. Conf. Microelectromech. Syst., Hong Kong, 2010, pp. 915-918.

[19] S. Smith, Y. Cui, and C. Bustamante, "Overstretching B-DNA: The elastic response of individual double-stranded and single-stranded DNA molecules," Science, vol. 271, no. 5250, pp. 795-799, 1996.

[20] N. Lafitte, M. Kumemura, L. Jalabert, D. Collard, and H. Fujita, "RealTime sensing of molecule binding on DNA with silicon nanotweezers," in Proc. 15th Int Conf. Miniaturized Syst. Chem. Life Sci., Seattle, WA, USA, 2011, pp. 389-372.

[21] Y. Sun, B. J. Nelson, D. P. Potasek, and E. Enikov, "A bulk microfabricated multi-axis capacitive cellular force sensor using transverse comb drives," J. Micromech. Microeng., vol. 12, no. 6, p. 832, 2002.

[22] W. Tang, T.-C. H. Nguyen, and R. Howe, "Laterally driven resonant microstructures," Sens. Actuators, vol. 20, pp. 25-32, 1989.

[23] G. Zhou and P. Dowd, "Tilted folded-beam suspension for extending the stable travel range of comb-drive actuators," J. Micromech. Microeng., vol. 13 , no. 2 , pp. $178-183,2003$.

[24] T. Clark and R. Howe, "An integrated CMOS micromechanical resonator high-Q oscillator," IEEE J. Solid-State Circuits, vol. 34, no. 4, pp. 440455, Apr. 1999.

[25] R. Legtenberg, A. Groeneveld, and M. Elwenspoek, "Comb-drive actuators for large displacements," J. Micromech. Microeng., vol. 6, no. 3, pp. 320-329, 1996.

[26] Y. Sun, S. N. Fry, D. P. Potasek, D. J. Bell, and B. J. Nelson, "Characterizing fruit fly flight behavior using a microforce sensor with a new comb-drive configuration," J. Micromech. Syst., vol. 14, pp. 4-11, 2005.

[27] M. Bao, Analysis and Design Principles of MEMS Devices. New York, NY, USA: Elsevier, 2005.

[28] N. Lafitte, "Modeling and control of MEMS tweezers for the characterizations of enzymatic reactions on DNA molecules," $\mathrm{Ph}$. D. dissertation, Université de Franche-Comté, Besançon, France, Apr. 2012.

[29] D. Collard, C. Yamahata, B. Legrand, T. Takekawa, M. Kumemura, N. Sakaki, G. Hashiguchi, and H. Fujita, "Towards mechanical characterization of biomolecules by MNEMS tools," IEEJ Trans. Electr. Electron. Eng., vol. 2, no. 3, pp. 262-271, Apr. 2007.

[30] D. Collard, "Silicon nanotweezers for biomechanical and bioelectrical assays," Front. Biosci., vol. E5, pp. 955-965, Jun. 2013.

[31] M. C. Tarhan, D. Collard, L. Jalabert, M. Kumemura, N. Lafitte, Q. Delouvée, S. L. Karsten, and H. Fujita, "Continuous real-time monitoring of molecular detection by silicon nanotweezers-integrated microfluidic device," in Proc. 16th Int. Conf. Miniaturized Syst. Chem. Life Sci., Okinawa, Japan, Oct. 2012, pp. 1897-1899.

[32] M. Washizu and O. Kurosawa, "Electrostatic manipulation of DNA in microfabricated structures," IEEE Trans. Ind. Appl., vol. 26, no. 6, pp. 1165-1172, Nov/Dec. 1990.

[33] R. Pankov, "Fibronectin at a glance," J. Cell Sci., vol. 115, no. 20, pp. 3861-3863, Oct. 2002

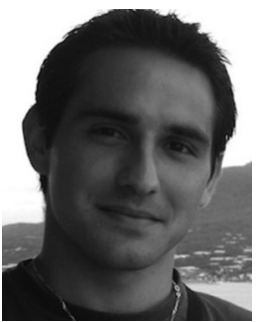

Nicolas Lafitte was born in Bordeaux, France, in 1983. He received the M.S. degree in electrical engineering speciality microelectronics from the University of Bordeaux 1, Bordeaux, and the graduate school ENSEIRB, Talence, France, in 2008, and the Ph.D. degree from the University of FrancheComté, Besançon, France, for his work on the modeling and the control of MEMS tweezers for characterizations of bioreactions on DNA molecules, in 2012. This work was conducted in LIMMS (CNRS/University of Tokyo joint laboratory) and in FEMTO-ST (CNRS/University of Franche-Comté). This publication deals with this work.

His current research interests include the MEMS integration for biological applications at the University of Tokyo, Japan.

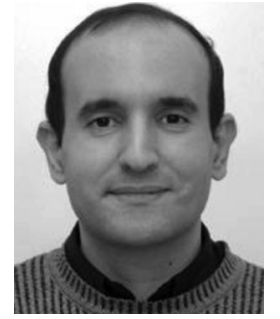

Yassine Haddab received the Engineering degree in electrical engineering from the University of Tizi-Ouzou, Tizi-Ouzou, Algeria, the M.S. degree from ENSMM, Besançon, France, and the Ph.D degree from the University of Franche-Comté, Besançon, France, in 2000. In 2012, he received the Habilitation a Diriger de Recherches degree from the University of Franche-Comté, Besançon.

Since 2002, he is an Associate Professor with ENSMM, Besançon, where he teaches control, microrobotics and embedded real-time systems. His research interests include the design, modeling, and control of high precision microrobots and microsystems. He also contributes to the development of microfactory concepts and new microrobots architectures.

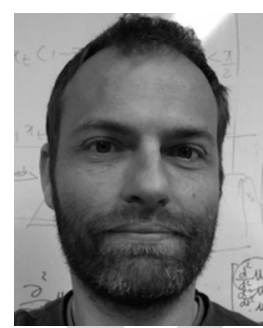

Yann Le Gorrec (M'XX) was graduated as engineer in "control, electronics, computer engineering"from the National Institute of Applied Sciences, Toulouse, France, in 1995, and received the Ph.D. degree from the National Higher School of Aeronautics and Aerospace, Supaero, Toulouse, in 1998.

From 1999 to 2008, he was an Associate Professor in Automatic Control at the Laboratory of Control and Chemical Engineering of Lyon Claude Bernard University, Villeurbanne, France. He worked on port Hamiltonian systems and their use for the modeling and control of irreversible and distributed parameter systems with an application to physico-chemical processes. Since september 2008, he has been a Professor with the National Engineering Institute in Mechanics and Microtechnologies. He is currently the Head of the COntrol DEsign research group of FEMTO-ST AS2M department. His research interests include robust control and self scheduled controller synthesis, the control of nonlinear systems, irreversible and infinite dimensional systems with an application to smart material-based actuators, and microactuators.

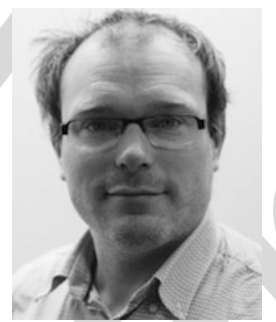

Hervé Guillou was born in Grenoble, France, in 1973. He studied fundamental physics from the University of Grenoble Alpes, Grenoble, France, the University of Karlsruhe, Karlsruhe, Germany, an at New York University, New York, NY, USA. He received the Master of Sciences degree from New York University and then a Ph.D. degree from the university of Grenoble Alpes, in 1998 and 2001, respectively.

Since 2004, he has been a Lecturer in physics with the University of Grenoble Alpes. His first research interests include low temperature physics and superconductivity. He moved then, to the field of biophysics where his interests include cell architecture, cell and molecular force generation, and development of methods, instruments, and microsystems for applications in biophysics and medicine.

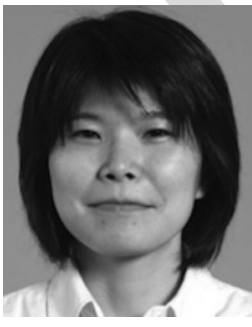

Momoko Kumemura was born in Kagoshima, Japan, in 1975. She received the M.S. degree in engineering from Tokushima University, Tokushima, Japan, and the Ph.D. degree in chemistry from Tokyo Metropolitan University, Tokyo, Japan, in 2002 and 2005, respectively.

She was a Postdoctoral Researcher in the Center for International Research on Micromechatronics, Institute of Industrial Science, The University of Tokyo (2005-2008 and 2010-2013) and in the Centre National de la Recherche Scientifique (20082010). Since 2014, she has been a Research Associate in Institute of Industria Science, The University of Tokyo. She is currently researching microsystems for biological applications. 


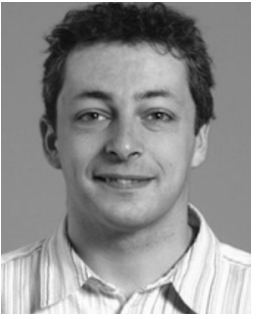

Laurent Jalabert was born in L'Union, France, in 1974. He received the Ph.D. degree from the Université Paul Sabatier, Toulouse, France, in 2001 dealing with CMOS gate engineering and reliability of ultrathin oxides.

From 2001 to 2003, he joined LIMMS (CNRSUniversity of Tokyo joint laboratory), Tokyo, Japan, as a Postdoctoral Researcher granted from the Japanese Society for the Promotion of Science and he developed piezoresistive MEMS cantilever for metrology in high aspect ratio microholes. In 2004 , he joined Institut National Polytechnique de Toulouse as a Research Engineer and worked at Laboratoire dAnalyse et dArchitecture des Systèmes on ICP-RIE plasma and alternative technologies (nanoimprint). Since 2007 till now, he is with the LIMMS as a CNRS Research Engineer hosted in Pr. Hiroyuki Fujita laboratory. His current research interests include atomic heat transfer in UHV TEM and MEMS fabrication (silicon nanotweezers, liquid-cells, etc.).

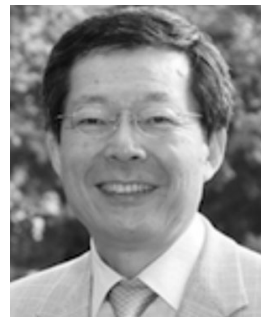

Hiroyuki Fujita (S'76-M'80) received B.S., M.S., 657 and Ph.D. degrees in electrical engineering from the 658 University of Tokyo, Tokyo, Japan, in 1975, 1977, 659 and 1980 , respectively.

Since 2000, he is the Director of the Center for 661 International Research on MicroMechatronics. Also, 662 since 1993, he has been a Professor, an Associate 663 Professor (1981-1993), and a Lecturer (1980-1981) 664 with the Institute of Industrial Science, the Univer- 665 sity of Tokyo. He is currently involved in the in- 666 vestigation of microelectromechanical systems fabri- 667 cated by IC-based processes and applications to optics, hard disk drives, and 668 bio/nanotechnology. His research interest includes autonomous distributed mi- 669 crosystems.

Dr. Fujita is a Fellow of the Institute of Electrical Engineers of Japan. 671

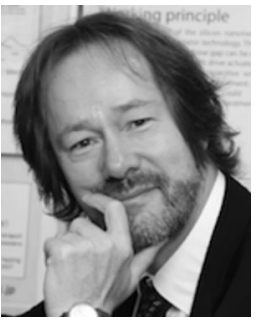

Dominique Collard ( $\left.\mathrm{M}^{\prime} 01\right)$ was born in Cambrai, France in 1958. He received the Engineering Degree from the Institut Supérieur dElectronique et du Numérique and the Ph.D. degree from the University of Lille, Lille, France, in 1980 and 1984, respectively.

From 1985 to 1986 , he was with the Toshiba VLSI Research Center, Kawasaki, Japan, as a Visiting Scientist. Since 1988, he has been with the Centre National de la Recherche Scientifique (CNRS), being alternatively with the Institut dElectronique, de Microélectronique et de Nanotechnologie, Lille, and with the Laboratory for Integrated MicroMechatronic Systems (LIMMS/CNRS-IIS), Tokyo. From August 2005, he joint a second time LIMMS where he was appointed as a Director in September 2007 and got a title of Project Professor of IIS, the University of Tokyo, Tokyo, Japan. In December 2011, he became Coordinator of EC/FP7 INCOLAB: EUJO-LIMMS aiming to open LIMMS to European partners and first EC laboratory in Japan. His current scientific interests include micro- and nano-systems for applications in biology and nanotechnology. He is the Author or Coauthor of more than 250 international publications.

Dr. Collard received the IBM price on intensive numerical calculation in 1990, the CNRS bronze medal in 1992, and was in 2004 Laureate of the French academic palms from Ministry of Higher Education and Research. 
Q1. Author: Please provide the full page range in Refs. [14], [16], and [21].

Q2. Author: Please provide the department name in Ref. [28].

Q3. Author: Please provide the year in which the author "Yann Le Gorrec" became a Member of the IEEE. 


\title{
Improvement of Silicon Nanotweezers Sensitivity for Mechanical Characterization of Biomolecules Using Closed-Loop Control
}

\author{
Nicolas Lafitte, Yassine Haddab, Yann Le Gorrec, Member, IEEE, Hervé Guillou, Momoko Kumemura, \\ Laurent Jalabert, Dominique Collard, Member, IEEE, and Hiroyuki Fujita, Member, IEEE
}

\begin{abstract}
In this paper, we show that closed-loop control can be advantageously used for the characterization of mechanical properties of biomolecules using silicon nanotweezers (SNT). SNT have already been used in open-loop mode for the characterization of mechanical properties of DNA molecules. Up to now, such an approach allows the detection of stiffness variations equivalent to about 15 DNA molecules. Here, it is shown that this resolution is inversely proportional to the resonance frequency of the whole system and that real-time feedback control with state observer can drastically improve the performances of the tweezers used as biosensors. Such improvement is experimentally validated in the case of the manipulation of fibronectin molecules. The results are promising for the accurate characterization of biopolymers such as DNA molecules.
\end{abstract}

Index Terms-Biosensor, MEMS tweezers, parameter detection, sensitivity improvement, state feedback.

\section{INTRODUCTION}

$\mathbf{R}$ ECENT developments in micronano manipulation tools have revealed crucial information on the mechanical behavior of biomolecules [1]-[3]. These manipulations generally performed on a single molecule have given the quantitative data needed to elucidate fundamental biological processes as DNA wrapping [4] and replication [5], or cell cytoskeleton dynamics through actin filament [6], and microtubule mechanical responses [7].

Several methods are already available for performing biological experiments at the molecular level: magnetic tweezers [8], [9], optical tweezers [10], AFM cantilevers [11], and microfibers [2], [12]. A single filamentary macromolecule, such as DNA, is first attached to a surface at one end, and to a bead

Manuscript received October 8, 2012; revised April 9, 2014; accepted June 10, 2014. Recommended by Technical Editor S. O. R. Moheimani. The work of Y. Haddab and Y. Le Gorrec was supported in part by the LABEX ACTION under Grant ANR-11-LABX-01-01 and the NANOROBUST Project (ANR2011 NANO 006).

N. Lafitte, H. Guillou, M. Kumemura, L. Jalabert, and D. Collard are with the LIMMS/CNRS-IIS (UMI 2820), Institute of Industrial Science, The University of Tokyo, Tokyo 153-8505, Japan (e-mail: lafitte@ iis.u-tokyo.ac.jp; herveg@iis.u-tokyo.ac.jp; momo@iis.u-tokyo.ac.jp; jalabert@iis.u-tokyo.ac.jp; collard@iis.u-tokyo.ac.jp).

Y. Haddab and Y. Le Gorrec are with the FEMTO-ST/UFC-ENSMMUTBM-CNRS, 25044 Besançon, France (e-mail: yassine.haddab@ens2m.fr; Yann.Le.Gorrec@ens2m.fr).

H. Fujita is with the Center for International Research on Micromechatronics, Institute of Industrial Science, The University of Tokyo, Tokyo 153-8505, Japan (e-mail: fujita@iis.u-tokyo.ac.jp).

Color versions of one or more of the figures in this paper are available online at http://ieeexplore.ieee.org.

Digital Object Identifier 10.1109/TMECH.2014.2351415 or a flexible cantilever at the other end. Forces or displacements are sensed by optical measurements. Nevertheless, the real-time operation and the routine implementation of these techniques remain difficult to achieve, as they require complex experimental procedures. In this respect, microelectromechanical systems (MEMS) offer an advantage for systematic analysis since accurate molecular level tools (actuator, end effectors, and sensor) can be integrated on a MEMS platform. Furthermore, these devices can be produced at low cost with batch fabrication, as have the microgrippers developed to grab microsized objects [13] or cells [14]. However, up to now, the performances of such tools are not sufficient to deal with single molecule characterization. In previous reports, silicon nanotweezers (SNT) were designed and fabricated to trap DNA molecules [15], [16] and characterize DNA bundles [17] and reactions on DNA [18]. The stiffness of DNA bundles was derived from the open-loop measurement of the mechanical resonance frequency shift. The current sensing resolution is in the range of $1 \mathrm{mN} \cdot \mathrm{m}^{-1}$, which corresponds to approximatively $15 \lambda$-DNA molecules ${ }^{1}[20]$. This resolution is limited by the design of the tweezers and the noise of the electronic instrumentation. To improve the overall system sensitivity towards lower stiffness, the primary route consists of reducing the tweezers stiffness to bring the sensor and measured object characteristics close to the same range. Unfortunately, such a design would result in a system that would be too fragile to be processed and utilized.

Our approach consists of scaling down the resonance frequency of the closed-loop system to enhance the sensitivity to SNT stiffness change. After a proper identification of the SNT model, the feedback control has been simulated, optimized, and then implemented. This control strategy has been evaluated with thin fibronectin molecular bundles trapped between SNT tips, and we propose to discuss the advantages and the limits of such closed-loop operations.

This paper is organized as follows. Section II describes the tweezers, the sensing principle, and provides an example of monitoring the DNA trapping. The dynamic model of the tweezers is then detailed in Section III-A. The closed-loop control strategy and its potential to improve the system sensitivity are discussed in Sections III-B and III-C. Section IV details the experimental implementation and provides information on fibronectin molecules measurement with different

\footnotetext{
${ }^{1} \lambda$-DNA is DNA of the bacteriophage $\lambda$ having a contour length of $16.4 \mu \mathrm{m}$ and a stiffness in elastic regime of $66 \mu \mathrm{N} \cdot \mathrm{m}^{-1}$ in low ionic solution [19].
} 


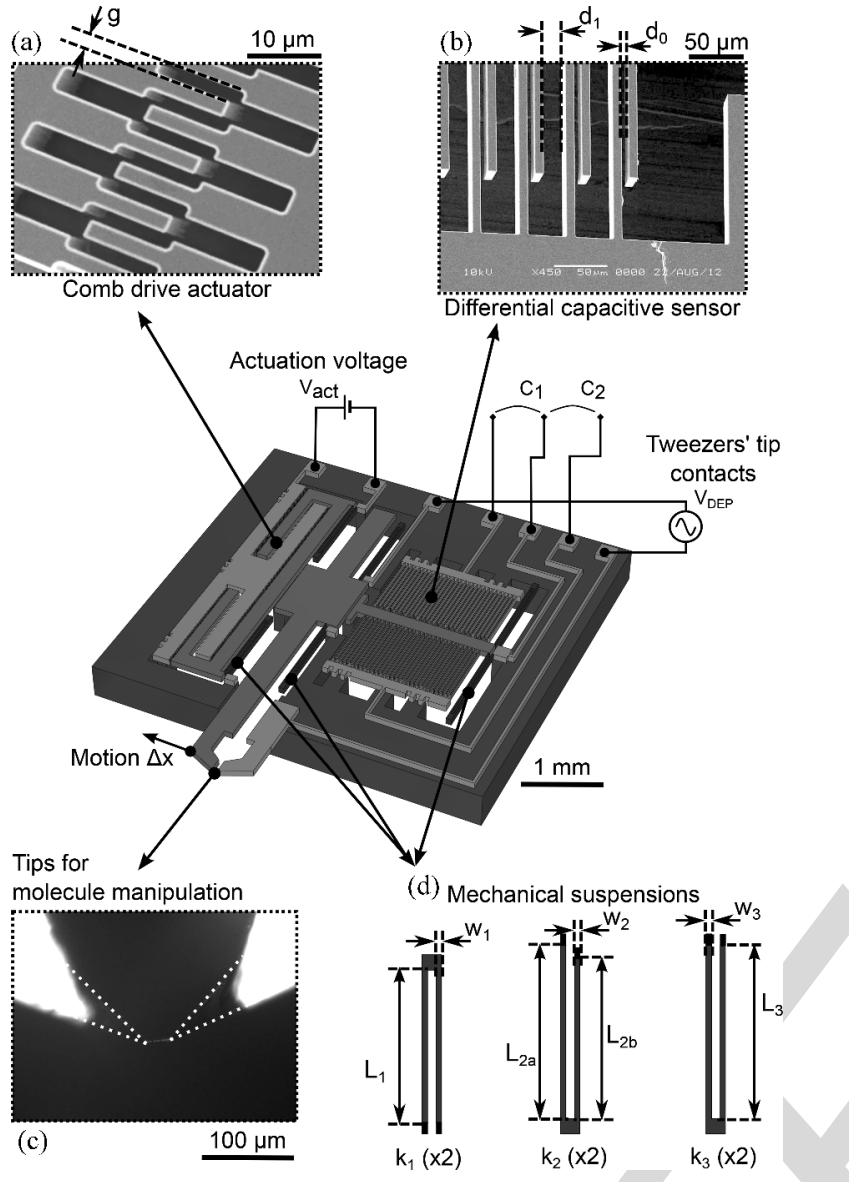

Fig. 1. SNT description. 3-D view of the device whose overall dimensions are $4.5 \times 4.5 \times 0.5 \mathrm{~mm}$. The mobile parts are shown in red and the mechanical suspensions in blue. (a) Scanning electronic microscopic (SEM) image of the actuator consisting of 880 pairs of interdigitated combs separated by a $2-\mu \mathrm{m}$ gap, and organized in two series. (b) SEM image of the integrated sensor of two opposing series of 30 combs. (c) Microscope image of the tweezers tips with a DNA bundle in between. (d) Design of the three sets of suspensions, $k_{1}$ for the actuator polarization, $k_{2}$ for the mobile arm, and $k_{3}$ for central sensor plate.

in MEMS design [22], [23]. The maximal stroke is limited compared to that achievable by a parallel plate actuator but the generated force only depends on the actuation voltage and not on the electrode position, thus, enabling a simpler actuation control. The force is given by (1) where $\varepsilon_{0}$ is the vacuum permittivity (we consider the relative permittivity of air $=1$ ), $N_{a}$ is the number of comb fingers, $t$ is the device thickness, $g$ is the lateral gap between fingers, and $V_{\text {act }}$ is the actuation voltage. Due to its capacitive structure, the comb drive generates attractive forces between its two electrodes

$$
F_{\mathrm{es}}=\frac{1}{2} \frac{\varepsilon_{0} \times N_{a} \times t}{g} V_{\mathrm{act}}^{2}=\alpha_{\mathrm{es}} \times V_{\mathrm{act}}^{2} .
$$

3) Mechanical Structure: The mobile part of the tweezers is linked to the silicon frame by flexible beams [see Fig. 1(d)]. Commonly integrated in mechanical microsystems [23], [24], folded beam springs are designed to minimize beam areas, decrease their mechanical stiffness and enhance displacement ranges [25]. In the SNT design of Fig. 1, three sets of folded beam suspensions support the mobile part of the system (the comb-drive actuator, the mobile tip, and the capacitive sensor) and provide the electrical connections for the actuation and the sensing. The springs are arranged symmetrically along the actuation and sensing axis to minimize any rotation, and their sum gives the total stiffness $k$ of the device.

A highly compliant system is required to sense the mechanical characteristic of trapped molecules on the tweezers response. On the other hand, a minimum stiffness is mandatory, 1) to endure the fabrication processes and manipulations, 2) to support the mobile system weight, and 3) to prevent sticking due to attractive surface forces between the comb-drive actuator and the capacitive sensor electrodes.

4) Displacement/Velocity Sensing: The tip position is measured by a capacitive sensor designed in a triplate configuration with transverse combs [see Fig. 1(b)] [26]. The central electrode, linked to the mobile arm, moves in between two fixed electrodes creating the two differential capacitances $C_{1}$ and $C_{2}$ whose difference, $\Delta C$, is related to the displacement $x$. For small displacements (i.e., $x$ is much smaller than the gaps between electrodes $d_{0}$ and $d_{1}$ ), $\Delta C$ is proportional to $x$ [17], $N_{b}$ is the number of capacitance electrodes, and $L$ the length of the electrodes

$$
\begin{aligned}
\Delta C & =C_{1}-C_{2} \\
& \simeq 2 \varepsilon_{0} N_{b} \operatorname{Lt}\left(\frac{1}{d_{0}^{2}}-\frac{1}{d_{1}^{2}}\right) x=\beta_{\mathrm{C}} \times x
\end{aligned}
$$

5) Electronic Read-Out: The tweezers motion is sensed by the measurement of the differential capacitance $\Delta C$ (2) through current sensing. In dynamic mode, a dc voltage $\left(V_{\text {polar }}\right)$ is applied on the mobile central electrode, whose motion generates dynamic currents $i_{1}$ and $i_{2}$ flowing through the capacitances $C_{1}$ and $C_{2}$, respectively, [27], [28]. The resulting currents related to the motion velocity are converted into voltages $V_{1}$ and $V_{2}$ by two low-noise current-to-voltage $(\mathrm{A} / \mathrm{V})$ preamplifiers (Signal Recovery, model 5182). The low input impedance of the preamplifier (virtual ground) ensures an accurate current conversion [17], [29]. attractive electrostatic forces generated in an interdigitated comb drive [see Fig. 1(a)], one of the most widely used architecture 
TABLE I

NuMERICAL VALUES OF DiMENSIONS AND PARAMETERS OF THE SNT

\begin{tabular}{lc}
\hline \hline Silicon thickness & \\
\hline$t(\mu \mathrm{m})$ & 30 \\
Comb drive actuator & \\
$N_{a}$ & 440 \\
$g(\mu \mathrm{m})$ & 2 \\
Mechanical suspensions & \\
$L_{1}, L_{2}$ a $(\mu \mathrm{m})$ & 900 \\
$L_{2 \mathrm{~b}}, L_{3}(\mu \mathrm{m})$ & 1000 \\
$w_{1}, w_{2}, w_{3}(\mu \mathrm{m})$ & 15 \\
Capacitive sensor & \\
$N_{b}$ & 30 \\
$L(\mu \mathrm{m})$ & 585 \\
$d_{0}(\mu \mathrm{m})$ & 5 \\
$d_{1}(\mu \mathrm{m})$ & 20 \\
\hline \hline
\end{tabular}

The device dimensions are defined in Fig. 1.

Finally, in harmonic mode, when the tweezers is moved by a sinusoidal actuation, a lock-in amplifier (NF, model LI 5640) performs the low-noise detection of the differential signal (amplitude and phase of $V_{1}-V_{2}$ ) at the actuation frequency. The reference signal is the motion frequency imposed by the actuation voltage.

All dimensions and parameters that has been considered for a proper model of the SNT are summed up in the TableI. Furthermore, Young's modulus and the density of the silicon are, respectively, $165 \mathrm{GPa}$ and $2329 \mathrm{~kg} \cdot \mathrm{m}^{-3}$, and the permittivity $\varepsilon_{0}$ is $8.85 \times 10^{-12} \mathrm{~kg}^{-1} \cdot \mathrm{m}^{-3} \cdot \mathrm{A}^{2} \cdot \mathrm{s}^{4}$.

\section{B. Monitoring Biomolecules Manipulation With SNT}

This Section presents the way that the SNT are used as biosensors and points out the measurement sensitivity requirements. This example is illustrated with DNA but the same technique has been applied to gelatin [30] and microtubules [31].

1) DNA Bundle Trapping by DEP: The trapping is achieved by applying an ac electric field $\left(E=1 \mathrm{MV} \cdot \mathrm{m}^{-1}\right)$ between the two opposing tips of the tweezers [32] once partially immersed in the solution. The retrieving of the DNA bundle is routinely performed from a droplet solution [15], [17], and single molecule trapping has even been demonstrated with a pulsed DEP signal [16].

In [20], an improved method is proposed in which the tips are introduced into an open fluidic cavity optimized to guaranty a stable meniscus. The SNT position is fixed and the cavity is mounted on a $X Y Z$ stage controlled by programmable robot for repeatable and controlled tip immersion, as illustrated in Fig. 2(a)-(c).

2) Real-Time Monitoring: The SNT characterization allows monitoring of the DNA trapping in real time. The characterization of the SNT in real time allows the monitoring of the DNA trapping. The number of trapped DNA molecules during the DEP is controlled by the evolution of the resonance frequency and quality factor of the system (Tweezers+DNA bundle). The SNT are modeled by a linear second-order model as depicted in Fig. 2(d). The resonance frequency, $f_{\mathrm{R}}$, and the quality factor

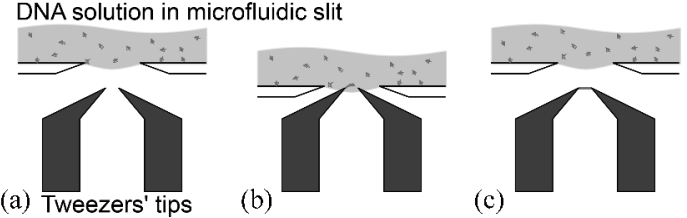

(a) Tweezers' tips
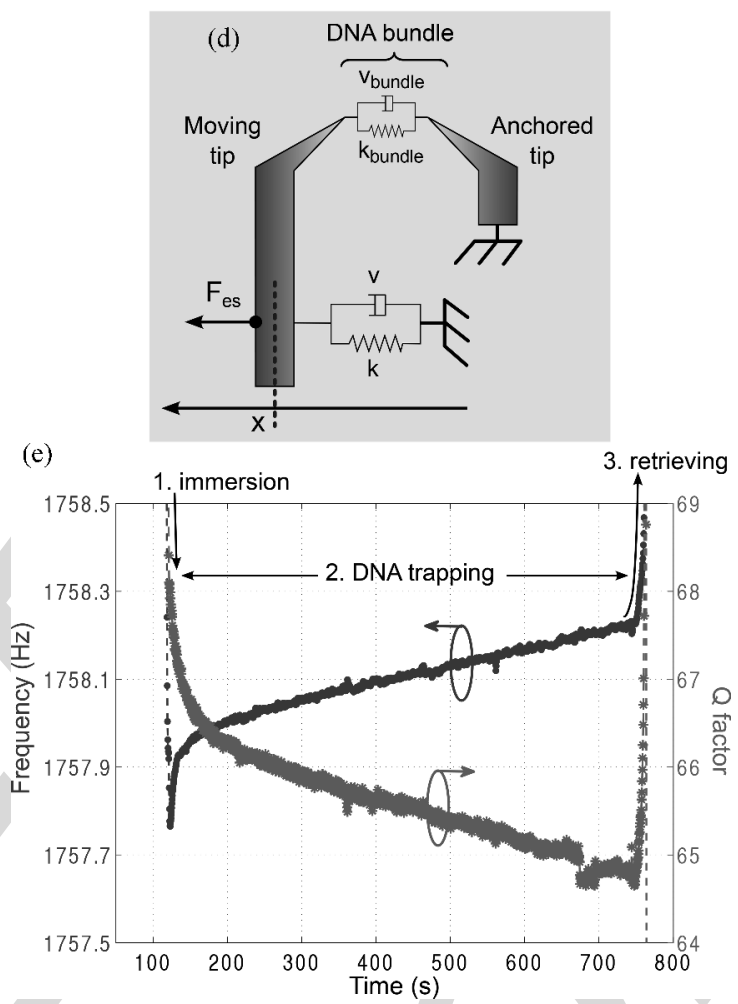

Fig. 2. $\lambda$-DNA molecules trapping with SNT. The first three sketches illus trate the key phases of the experiment: (a) the immersion of the tips in the DNA solution, (b) the DNA trapping by DEP, and (c) the retrieving of DNA bundle between the tips. (d) Equivalent dynamic model of the SNT with bundle. (e) Evolution of the $S N T+$ bundle resonance frequency and $Q$ factor during the trapping.

$Q$ of the $S N T+$ bundle damped oscillator are defined by

$$
\begin{aligned}
f_{\mathrm{R}}(t) & =\frac{1}{2 \pi} \sqrt{\frac{\left(k+k_{\text {bundle }}(t)\right)}{M}} \\
Q(t) & =\frac{\sqrt{\left(k+k_{\text {bundle }}(t)\right) \times M}}{\left(\nu+\nu_{\text {bundle }}(t)\right)}
\end{aligned}
$$

where $M$ is the mass of the movable tip, $k$ is the stiffness of the suspensions, and $\nu$ is the equivalent viscous losses. $k_{\text {bundle }}$ and $\nu_{\text {bundle }}$ are the time varying bundle stiffness and viscosity; the mass of the bundle is neglected compared to $M$.

As shown in Fig. 2(e), as the DEP trapping progresses, the system moves to higher resonance frequencies indicating an increase in the bundle stiffness according to (4). At the same time, the signal amplitude at resonance, proportional to the quality factor $Q$, is decreasing, revealing higher viscous losses $\nu_{\text {bundle }}$ as the bundle forms, in accordance with (5).

In this experiment, the resonance frequency experiences a shift of $0.4 \mathrm{~Hz}$ that corresponds to an increase in the stiffness of $12 \mathrm{mN} \cdot \mathrm{m}^{-1}$, i.e., a bundle containing $\sim 200 \lambda$-DNA molecules 
4 and
[19]. (For the sake of clarity, it should be noted that the SNT used in this trapping experiment has different characteristics than those used in the feedback approach of Sections III and IV)

3) Sensor Resolution: Accurate biosensing by SNT requires high-resolution measurements. Thus, special care in signal conditioning (detection of small currents $<10 \mathrm{pA}$ ), noise reduction, and control of the experimental conditions (e.g., the stability of the meniscus air/biological liquid/tweezers) have allowed to sense resonance frequency shifts of $25 \mathrm{mHz}$ and quality factor changes of 0.2. Based on this resolution, the minimum change that can be sensed due to the stiffness variation is in the range of 15 molecules of $\lambda$-DNA [20].

After trapping, the bundle of molecules is mechanically stimulated (in air or in a biological solution) with a sinusoidal signal at the resonance frequency of the system. Slight changes in the frequency response permit a fine characterization of the evolution of the mechanical properties of the molecule bundle revealing biological interactions.

\section{DynAmic Modeling AND IMPROVEMENT OF THE PARAMETRIC SENSITIVITY By A FEEDBACK APPROACH}

In this Section, we describe how to reduce the closed-loop resonance frequency of the tweezers in order to improve its sensitivity to molecule stiffness variations.

\section{A. Dynamic Modeling and Open-Loop Sensitivity to Stiffness Variations}

1) Modeling: Newton's second law applied to the damped oscillator formed by the $S N T+$ bundle of Fig. 2(d) can be formulated by

$$
\dot{X}=\underbrace{\left[\begin{array}{c}
0 \\
-\frac{\left(k+k_{\text {bundle }}(t)\right)}{M}-\frac{\left(\nu+\nu_{\text {bundle }}(t)\right)}{M}
\end{array}\right]}_{A} X
$$$$
+\underbrace{\left[\begin{array}{c}
0 \\
\frac{1}{M}
\end{array}\right]}_{B} F_{\mathrm{es}}
$$

$$
y=\underbrace{\left[\begin{array}{ll}
0 & 1
\end{array}\right]}_{C} X
$$

where $A \in \mathbb{R}^{2}, B \in \mathbb{R}^{(2,1)}, C \in \mathbb{R}^{(1,2)}, X$ is the state vector (displacement \& velocity, $X=\left(\begin{array}{l}x \\ \dot{x}\end{array}\right)$ ), and $y$ is the output vector or the measurement.

2) Identification: Prior to the development of an accurate control strategy, the model parameters $[M, k, v$, actuation, and sensor gains of (1)-(5)] need to be extracted from device measurements. These parameters are identified through standard recursive approach with least squares method from SNT responses to small signal actuation with a $20 \mathrm{~V}$ offset. Identified parameters are summarized in Table II.
TABLE II

THEORETICAL AND IDENTIFIED MODEL PARAMETER VALUES OF THE SNT

\begin{tabular}{lcc}
\hline \hline Parameters & Theoretical & Identified \\
\hline $\begin{array}{l}\text { Mechanical parameters } \\
\mathrm{M}(\mathrm{kg})\end{array}$ & $360 \times 10^{-9}$ & $360 \times 10^{-9}$ \\
$\mathrm{k}\left(\mathrm{N} \cdot \mathrm{m}^{-1}\right)$ & $49.3^{a}$ & 24.9 \\
$\nu\left(\mathrm{Ns} \cdot \mathrm{m}^{-1}\right)$ & - & $100 \times 10^{-6}$ \\
Comb-drive actuator & $29.2 \times 10^{-9 a}$ & $35.5 \times 10^{-9}$ \\
$\alpha_{\mathrm{es}}\left(\mathrm{N} \cdot \mathrm{V}^{-2}\right)$ & & \\
Capacitive sensor & $412.2 \times 10^{-9 a}$ & $227.5 \times 10^{-9}$ \\
$\beta_{\mathrm{C}}\left(\mathrm{F} \cdot \mathrm{m}^{-1}\right)$ & & \\
\hline \hline
\end{tabular}

${ }^{a}$ These values are calculated from the designed springs and electrodes widths and does not take into account the significant beam narrowing during etching processes.

3) Open-Loop Sensitivity to Stiffness Variation: The mini- 235 mum number of molecules that can be discerned by resonance 236 frequency shifts due to the molecular stiffness variation is linked 237 to the SNT sensitivity to stiffness variation $\Delta k$, i.e.,

$$
\frac{\partial f_{\mathrm{R}}}{\partial k}=\frac{1}{4 \pi \sqrt{k M}} \text { or } \frac{1}{8 \pi^{2} M f_{\mathrm{R}}} .
$$

This sensitivity is equal to $26.4 \mathrm{~Hz} /\left(\mathrm{N} \cdot \mathrm{m}^{-1}\right)$ with the iden- 239 tified parameters of Table II. It appears that for a given molecu- 240 lar stiffness change, $\Delta k$, the effect on the resonance frequency 241 variation $\Delta f_{\mathrm{R}}$ is enhanced with low SNT stiffness, $k$, and, there- 242 fore, for low resonance frequency $f_{\mathrm{R}}$. In relation to Fig. 2, the 243 current experimental resolution in the resonant frequency shift 244 measurement is close to $25 \mathrm{mHz}$, a value that corresponds to 245 $1 \mathrm{mN} \cdot \mathrm{m}^{-1}$ or $15 \lambda$-DNA molecules. From (8), a reduction of 246 $f_{\mathrm{R}}$ by one order of magnitude; i.e. 2 orders of magnitude for 247 $k$, would improve the detection threshold down to the single molecule level.

The development of a new MEMS device having a very low stiffness $\left(<0.2 \mathrm{~N} \cdot \mathrm{m}^{-1}\right.$ remains extremely challenging in terms of fabrication and operation. Thus, we propose to reduce the overall stiffness by closed-loop control. In such a control strategy, the physical system (i.e., the SNT) remains the same but the closed-loop system SNT combined with the feedback law will have the desired designed dynamic behavior.

\section{B. Improvement of the Parametric Sensitivity by a Feedback Approach}

1) Control Strategy: The control design strategy is depicted 259 in the flowchart of Fig. 3. The aim of the feedback is to reduce the 260 resonance frequency of the closed-loop system. To this end, we 261 use a state feedback eigenstructure assignment in order to assign 262 both the closed-loop resonance frequency and damping factor. 263 This state feedback is then implemented using a Luenberger- 264 kind observer. The originality of the observer we use is that it 265 has to be designed in order to neither deteriorate the closed-loop 266 sensitivity nor amplify the noise.

2) Eigenstructure Assignment Using State Feedback: The 268 system is under its controllable canonical state-space represen- 269 tation $(A, B, C)$ given by (6) and (7). The state feedback gain 270 vector $L=\left(l_{1}, l_{2}\right) \in \mathbb{R}^{(1,2)}$ is designed to assign the desired 271 


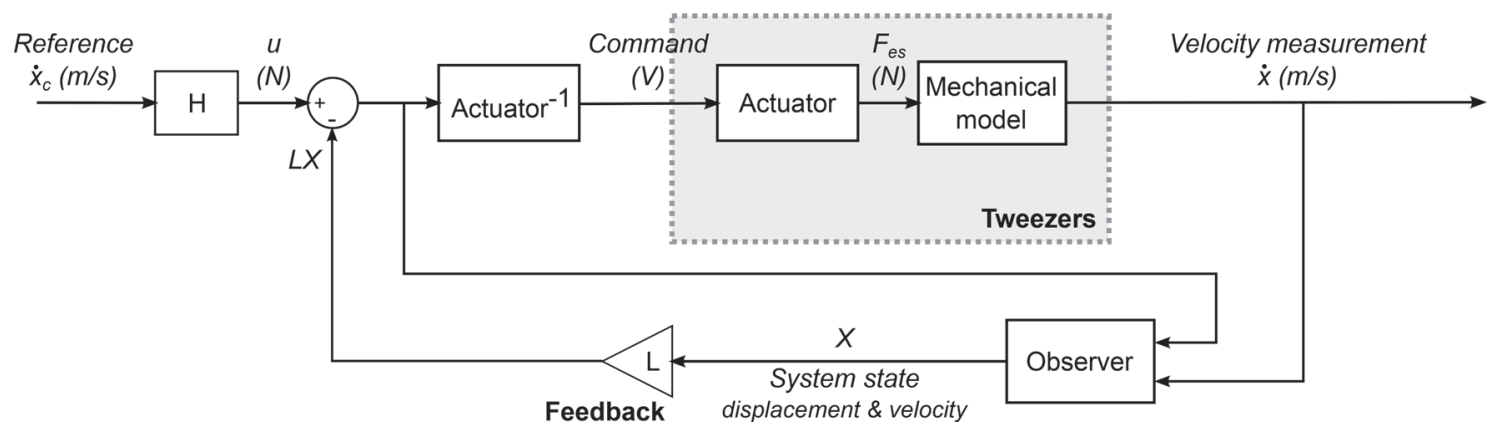

Fig. 3. Feedback control scheme. Gray box, called Tweezers, comprises the mechanical and the actuator models. Actuator square law needs to be inverted in order to linearize the control signal. The state feedback gain vector $L$ and the feedforward gain $H$ are designed to assign the desired closed-loop poles and to ensure unitary static gain. The observer is a Luenberger observer reconstructing the state of the system $X$ for the state feedback. The sensor model is not shown here. The device output voltage is converted into the tip velocity by dividing by the sensor gain $1 / \beta_{C}$.

TABLE III

Pole Placement of the Closed-Loop System and State Feedback Gain $L$ ACCORDING TO THE RESONANCE FREQUENCY REDUCTION $n$

\begin{tabular}{lcc}
\hline \hline Freq. & $L\left(\left[\mathrm{~N} \cdot \mathrm{m}^{-1}\right],\left[{\left.\left.\mathrm{Ns} \cdot \mathrm{m}^{-1}\right]\right)}^{\text {Poles }}\right.\right.$ \\
\hline$f_{\mathrm{R}}$ & $(0,0)$ & $-138.9 \pm 8.3 \times 10^{3} i$ \\
$f_{\mathrm{R}} / 1.2$ & $\left(-7.6,-16.7 \times 10^{-6}\right)$ & $-115.7 \pm 6.9 \times 10^{3} i$ \\
$f_{\mathrm{R}} / 2.0$ & $\left(-18.7,-50.0 \times 10^{-6}\right)$ & $-69.4 \pm 4.2 \times 10^{3} i$ \\
$f_{\mathrm{R}} / 3.2$ & $\left(-22.5,-68.8 \times 10^{-6}\right)$ & $-43.4 \pm 2.6 \times 10^{3} i$ \\
$f_{\mathrm{R}} / 5.0$ & $\left(-23.9,-80.0 \times 10^{-6}\right)$ & $-27.8 \pm 1.7 \times 10^{3} i$ \\
$f_{\mathrm{R}} / 10$ & $\left(-24.7,-90.0 \times 10^{-6}\right)$ & $-13.9 \pm 0.8 \times 10^{3} i$ \\
\hline \hline
\end{tabular}

closed-loop poles. The actuation of the system $F_{\mathrm{es}}$ is equal to $u-L X$, and the closed-loop system model becomes

$$
\dot{X}=\left[\begin{array}{cc}
0 & 1 \\
-\frac{k+l_{1}}{M} & -\frac{\nu+l_{2}}{M}
\end{array}\right] X+\left[\begin{array}{c}
0 \\
\frac{1}{M}
\end{array}\right] u \text {. }
$$

Thus, the closed-loop resonance frequency and sensitivity are given by

$$
\begin{aligned}
f_{\mathrm{R}-\mathrm{cl}} & =\frac{1}{2 \pi} \sqrt{\frac{\left(k+l_{1}\right)}{M}} \\
\frac{\partial f_{\mathrm{R}-\mathrm{cl}}}{\partial k} & =\frac{1}{4 \pi \sqrt{\left(k+l_{1}\right) M}}=\frac{1}{8 \pi^{2} M f_{\mathrm{R}-\mathrm{cl}}} .
\end{aligned}
$$

The state feedback gain $L$ is, then, determined in order to assign the closed-loop poles in such a way that the system resonates at a lower frequency than the natural frequency of the tweezers (see Table III). $L$ is computed to scale down this resonant frequency (initially $1323.6 \mathrm{~Hz}$ ), by a given factor depending on the desired sensitivity enhancement while keeping the damping factor unchanged.

When the closed-loop resonance frequency is scaled down by a factor $n$ compared to the SNT natural resonance frequency, the sensitivity to small stiffness variation is improved with the same ratio according to (11). Fig. 4 shows the computed frequency shift of the closed-loop system caused by a significant stiffness variation for different frequency scaling down factor, $n$.

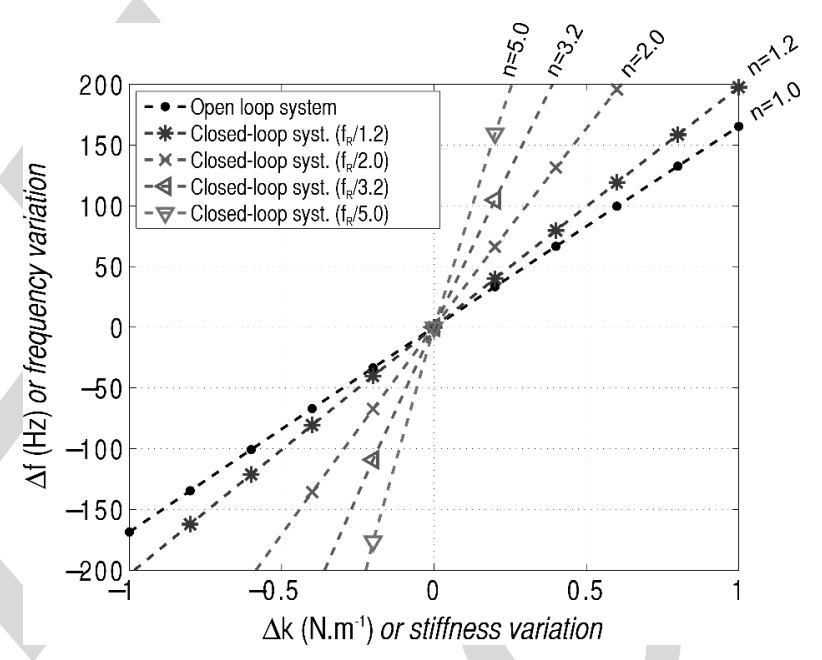

Fig. 4. Evolution of the resonance frequency shift $\Delta f_{\mathrm{R}}$ and $\Delta f_{\mathrm{R}-\mathrm{cl}}$ with the added stiffness $\Delta k$ variation for different frequency reduction ratio $n$.

\section{Observer Design}

The implementation of the aforementioned state feedback is done through the use of a Luenberger observer. The observer is designed such that it preserves the good closed-loop sensitivity to parametric variations and it does not amplify too much noise.

The poles of the observer have then to be carefully chosen. We used the following guidelines.

(1) The observer is designed to be faster than the original device - with poles at least two times faster than the poles of the system in open loop (cf., Table III).

(2) The observer poles are chosen not too fast in order to avoid excessive noise amplification.

(3) The final location of the observer poles is chosen in order to preserve the sensitivity of the system to stiffness variations (by using root locus).

In the following section, simulations illustrate 1) the relevance of the method and 2) the importance of the design of the observer towards the enhancement of the sensitivity. 


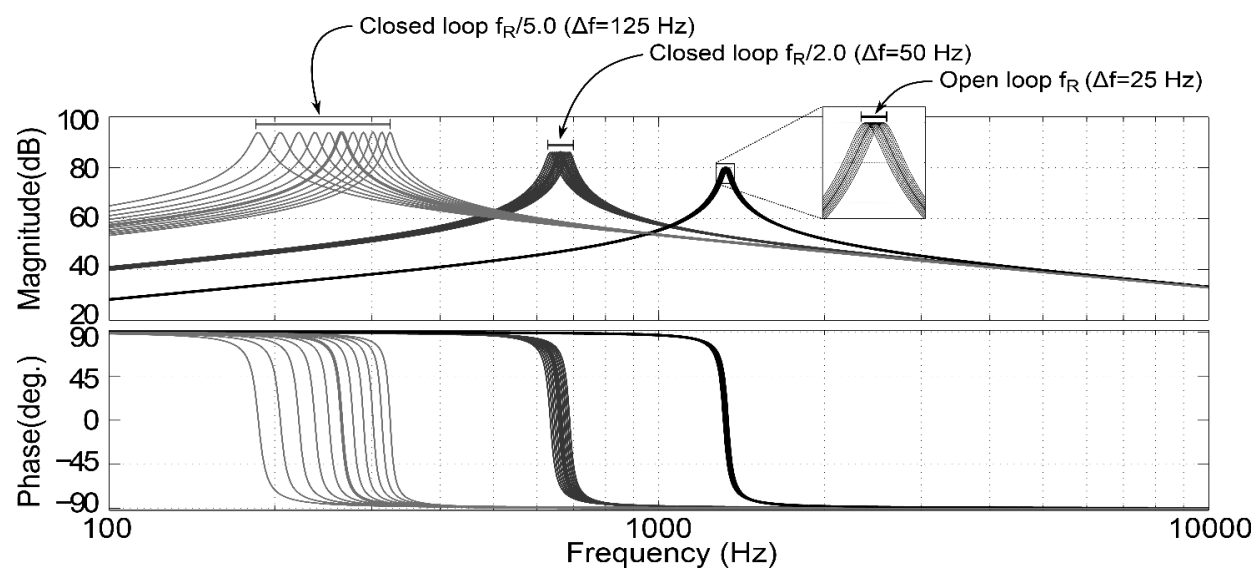

Fig. 5. Simulated frequency results for open-loop driven system and two different closed-loop systems. The three systems undergo a variation of $k$ the system stiffness. $k$ vary from -0.5 to $0.5 \mathrm{~N} / \mathrm{m}$ by $0.1 \mathrm{~N} / \mathrm{m}$ step. In black line, the tweezer transfer function, i.e., the open-loop system. In blue line, the implemented $(n=2)$ closed-loop system transfer function. The system resonates at a frequency twice lower. In red line, the implemented $(n=5)$ closed-loop system transfer function. The system resonates at a frequency five times lower.

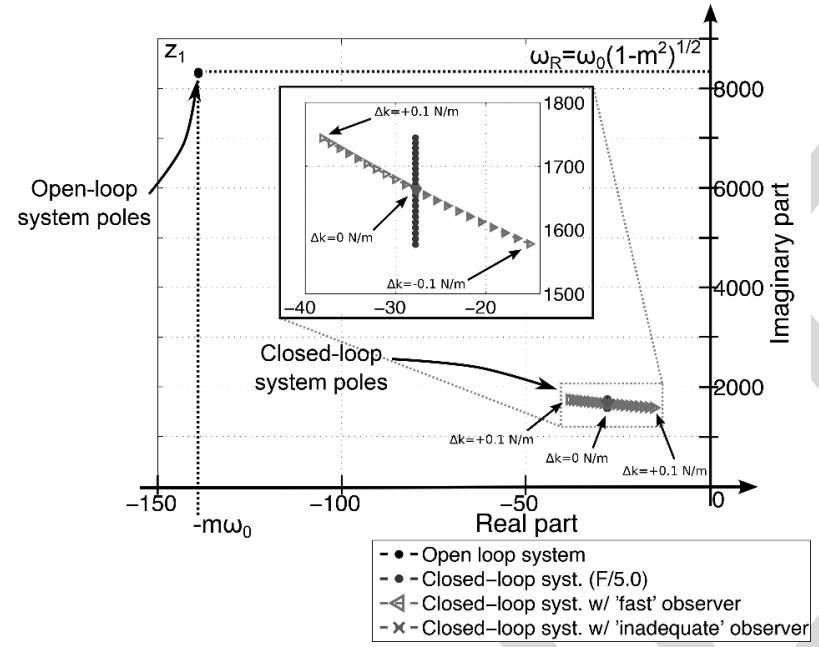

Fig. 6. Root locus of the closed-loop systems with $n=5$ and with different observers. Complex conjugate poles are plotted in the positive imaginary half $s$ plan. The parameter $k$ varies from -0.1 to $0.1 \mathrm{~N} / \mathrm{m}$ by $0.01 \mathrm{~N} / \mathrm{m}$ steps. The black dots show the poles of the open-loop driven system. The ideal pole path of the closed-loop system due to the $k$ variations are plotted with blue dots (i.e., no observer). For different observers designs, poles dependencies (and equivalent resonance frequency $\omega_{\mathrm{R}}=2 \pi f_{\mathrm{R}}$ and damping $m$ ) on the tweezers stiffness $k$ are shown by red triangle and green cross plots. NB: Green cross dots path are imperceptible since they are at this scale all concentrate in the middle.

\section{Simulation Results}

From parameters identified in Table II, the feedback scheme (see Fig. 3) has been first programmed and tested under MATLAB/Simulink without implementing the observer (i.e., all the state variables are supposed to be measured). Fig. 5 compares the resonance frequency shift between the open-loop driven system and the closed-loop systems computed for two resonance frequency reduction factors set to $n=2$ and 5 . As expected, the sensitivity of the closed-loop system is improved proportionally to $n$.

In a second instance, we implemented two different kinds of observers (with different dynamics); Fig. 6 illustrates two cases.
TABLE IV

Pole Placement OF THE OBSERVER FOR STATE FeEdBack IMPLEMENTATION

\begin{tabular}{lc}
\hline \hline Open-loop system (Tweezers) & $z_{1,2}=-138.9 \pm 8.3 \times 10^{3} i$ \\
\hline closed-loop system $(n=5)$ & $z_{1,2}=-27.8 \pm 1.7 \times 10^{3} i$ \\
Observer 1 (fast) & $z_{1,2}=-277.8 \pm 0.2 \times 10^{3} i$ \\
Observer 2 (slow) & $z_{1,2}=-27.8 \pm 0.2 \times 10^{3} i$ \\
Observer 3 (inadequate) & $z_{1,2}=-277.8 \pm 16.7 \times 10^{3} i$ \\
\hline \hline
\end{tabular}

This Figure shows that the root locus (due to $k$ parameter varia- 320 tions) is deformed by the observer dynamics. The sensitivity of 321 the resonance frequency to stiffness variations is given by the 322 amplitude of the imaginary axis variations. Table IV reports the 323 poles of the observers for which simulation results are presented. 324

In the insert of Fig. 6, the poles of the system implemented 325 with the observer named inadequate do not move compared to 326 the ideal root locus (ideal state feedback case). If the poles of 327 the observer are inappropriately chosen, the sensitivity of the 328 poles to variations of $k$ is significantly reduced. Observer poles 329 close to the real axis, i.e., with an imaginary part close to 0,330 are the more appropriate to reconstruct the displacement state 331 and to preserve the sensitivity of the system to variations of $k$. 332 The socalled fast observer allows us to increase the resonance 333 frequency shift ( $\omega_{\mathrm{R}}=2 \pi f_{\mathrm{R}}$ in Fig. 6 ) close to the performances 334 theoretically expected.

\section{EXPERIMENTAL APPLICATION FOR EXTRA-STIFFNESS CHARACTERIZATION}

The previous method has been experimentally tested with the 338 mechanical characterization of biomolecules of fibronectin. The 339 physical sensor is the SNT, while the feedback controller and 340 the observer are implemented in a dSPACE prototyping board. 341

\section{A. Experimental Protocol}

Fibronectin is a protein, $100 \mathrm{~nm}$ in length, of the extracel- 343 lular matrix which plays a major role in cell adhesion, growth, 344 


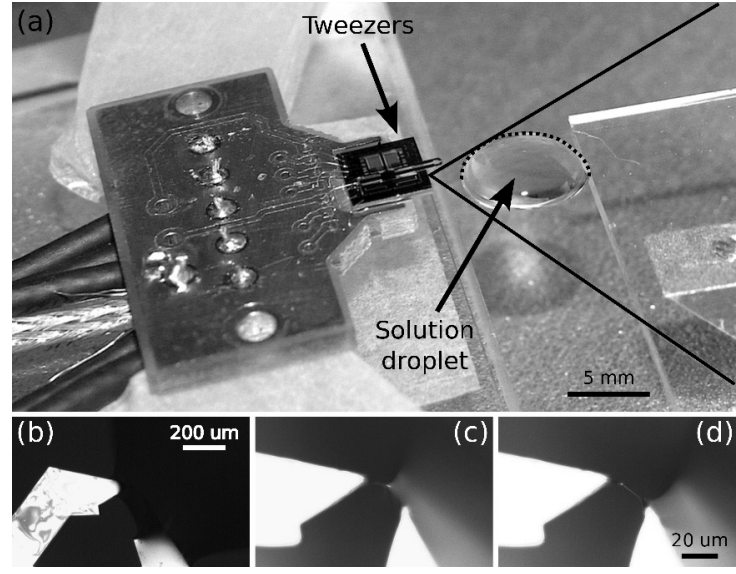

Fig. 7. Experimental setup for the trapping of fibronectin molecules. (a) The SNT are fixed. A droplet of fibronectin solution is dropped on a glass slice which is mounted on the XYZ stage. (b)-(d) Sequences of the molecule combing. Under optical microscopy, the tweezers' tips are retrieved from the solution meniscus. A bundle of fibronectin is released between the tips.

migration, and differentiation [33]. These molecules are used to polymerize the fibrillar matrix at the surface of the cell. We have used this property to trap by combing a bundle of fibronectin. After immersion of the tips in the solution, they are retrieved by the side forming a polymerized bundle of molecules (see Fig. 7).

The closed-loop systems are evaluated with fibronectin bundle in air, in dry condition. This stable condition was preferred to the immersed one as we can avoid any effect of liquid surface tension stability that can interfere with the sole system response. For each case, a sinusoidal reference of $0.02 \mathrm{~V}_{\mathrm{AC}}$ with an offset of $20 \mathrm{~V}_{\mathrm{DC}}$ is applied to the system and the oscillation frequencies are spanned from 1000 to $2000 \mathrm{~Hz}$ with a step of $2 \mathrm{~Hz}$. Then, the measurement is performed with the lock-in amplifier.

Two sets of experiments have been performed with two different bundles. From the resonance frequency shifts in open loop, the stiffness of the first bundle is $11.8 \mathrm{~N} \cdot \mathrm{m}^{-1}$, and $4.3 \mathrm{~N} \cdot \mathrm{m}^{-1}$ for the second one. In total, 22 resonance responses are recorded and compared.

\section{B. Results and Discussions}

1) Experimental Results: Fig. 8 shows the frequency responses of four different systems with and without a bundle of fibronectin.

In Fig. 8(a), the responses of the open-loop driven SNT are given. The dashed-line curve is the reference curve, which corresponds to the frequency response of the SNT alone driven in open loop. The solid line is the response of the tweezers with the bundle trapped in between the tips. The resonance frequency increases and the amplitude decreases due to the additional stiffness and loss contributions of the molecules. In Fig. 8(b)-(d), the results of the closed-loop systems with desired reduction ratios are of 1.1, 1.2 and 1.5.

Resonance responses are fitted with a second-order resonator model and characteristics such as the resonance frequency are extracted. The Table V sums up the resonance frequencies for the experiment with/without the first bundle for five different
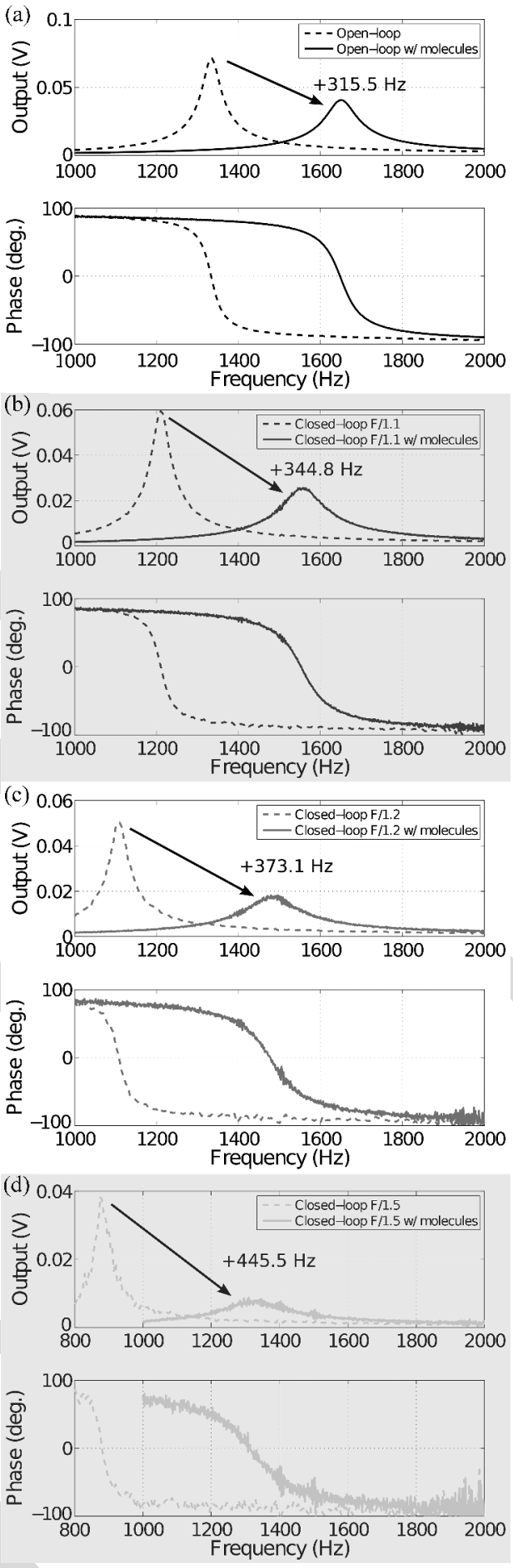

Fig. 8. Frequency responses of different implemented closed-loop systems for $0.02 \mathrm{~V}$ sinusoidal signal with an offset of $20 \mathrm{~V}$. In dotted lines, the responses of the systems with the bundle of molecules. In plain lines, the responses of the systems without molecules. (a) Open-loop driven systems. (b) Closed-loop systems implemented with $f_{\mathrm{R}} / 1.1$. (c) Closed-loop systems implemented with $f_{\mathrm{R}} / 1.2$. (d) Closed-loop systems with $f_{\mathrm{R}} / 1.5$.

systems. Through reducing the resonance frequency of the sys- 380 tem, the measured results prove the increase of the frequency 381 shift due to the extra-stiffness of the bundle.

Moreover Fig. 9 tends to 1) confirm with second set of experiments, the enhancement of the sensitivity through the proposed 
TABLE V

EXPERIMENTAL RESUlTS FOR THE BUNDLE 1 (RELATED TO FIG. 8)

\begin{tabular}{lccc}
\hline \hline System $(n)$ & $\begin{array}{c}\text { Freq. } \\
\text { w/o bundle }(\mathrm{Hz})\end{array}$ & $\begin{array}{c}\text { Freq. } \\
\text { w/ bundle }(\mathrm{Hz})\end{array}$ & $\begin{array}{c}\text { Freq. shift } \\
(\mathrm{Hz})\end{array}$ \\
\hline Open loop (1.0) & 1333.6 & 1649.1 & +315.5 \\
Closed-loop (1.1) & 1211.1 & 1555.9 & +344.8 \\
Closed-loop (1.2) & 1109.1 & 1482.2 & +373.1 \\
Closed-loop (1.5) & 881.9 & 1327.4 & +445.5 \\
Closed-loop (2.0) & 653.9 & 1175.6 & +521.7 \\
\hline \hline
\end{tabular}

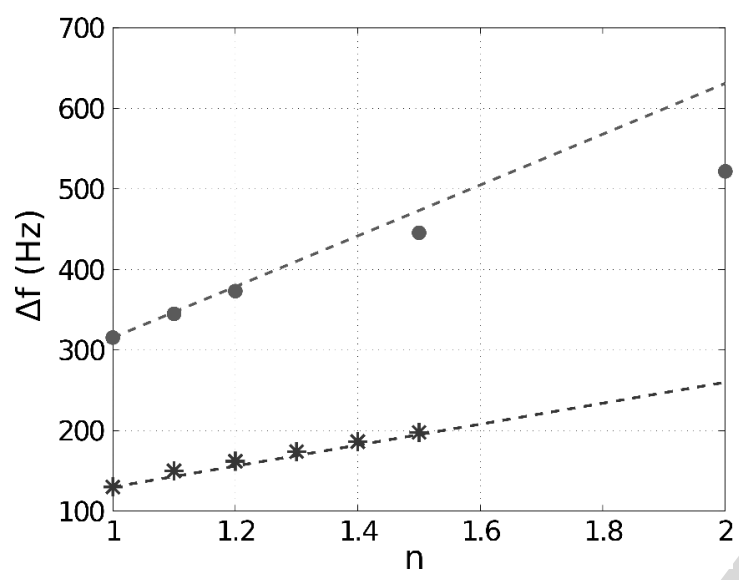

Fig. 9. Synthesis of the experimental results. In abscissa, is informed the reduction factor $(n)$ applied to the resonance frequency for the closed-loop system. The shift $\Delta f$ is the resonance frequency difference due to the presence of the bundle of molecules in between the tips. The dotted lines represent the theoretical improvement expected. The two sets of results obtained with two different bundles are plotted. The green dots correspond to the experiment of Fig 8 and TableV (bundle of $11.8 \mathrm{~N} \cdot \mathrm{m}^{-1}$ stiffness). The blue stars corresponds to the second bundle of $4.3 \mathrm{~N} \cdot \mathrm{m}^{-1}$ stiffness.

feedback strategy and 2) show a good agreement with the theory. Small differences are discussed in the following section.

2) Discussion: The synthesis of Fig. 9 demonstrates the enhancement of the frequency shifts in agreement with the theory. However, the enhancement for closed-loop system with a reduction factor of 2.0 is lower than expected, and the implementation for a higher reduction factor has not been achieved. In this case, the system tends to become unstable. We mainly associated this phenomenon to the observer implementation and to the presence of some delays in the feedback loop.

We have demonstrated previously that observer's dynamic changes the root locus of system's poles, the behavior of the closed-loop system under parameter variations and impacts the performances of the method. Furthermore, delays have been characterized due to D/A and A/D converters dead times and to the phase shift brought by the current amplifiers. Current works are devoted to the precise characterization of such delays and to their integration in the control design process.

\section{CONCLUSION AND FutuRE WORK}

The present study investigates the relevance of a feedback approach in the improvement of the performances of MEMS tweezers for the detection and the mechanical characterization of biological molecules. An improvement of $50 \%$ on the sensitivity to mechanical stiffness variations has been reached theoretically and experimentally on fibronectin bundles through the emulation of a more compliant system. The stiffness have been brought down to $10.5 \mathrm{~N} / \mathrm{m}$ instead of originally $24.5 \mathrm{~N} / \mathrm{m}$.

The main drawback of this approach is the sensitivity of 412 the observer to the stiffness variations. Unusually, the poles of 413 the observer are uncontrollable resulting from the separation 414 principle. During the sensing of the molecules stiffness, the 415 separation principle is not satisfied anymore and the observer 416 poles can become unstable. We are actually working on self- 417 scheduled observers aiming at adapting the observer dynamics 418 with respect to sensed parametric variations. It should solve the 419 main drawback of this promising approach and allows us to go 420 one step further into the theoretical closed-loop performances.

\section{ACKNOWLEDGMENT}

The authors would like to thank A. W. Coleman from the University of Lyon, Lyon, France, for the discussion and proofreading of the text. The photolithography masks were fabricated with the 8-inch EB writer F5112+VD01 donated by Advantest Corporation to the VLSI Design and Education Center (the University of Tokyo).

\section{REFERENCES}

[1] C. Bustamante, J. Marko, E. Siggia, and S. Smith, "Entropic elasticity of lambda-phage DNA," Science, vol. 265, no. 5178, pp. 1599-1600, 1994.

[2] P. Cluzel, A. Lebrun, C. Heller, R. Lavery, J. L. Viovy, D. Chatenay, and F. Caron, "DNA: An extensible molecule," Science, vol. 271, no. 5250 , pp. $792-794$, Feb. 1996

[3] G. Bao, "Mechanics of biomolecules," J. Mech. Phys. Solids, vol. 50, no. 11, pp. 2237-2274, 2002.

[4] A. Bancaud, N. Conde E Silva, M. Barbi, G. Wagner, J.-F. Allemand, J. Mozziconacci, C. Lavelle, V. Croquette, J.-M. Victor, A. Prunell, and J.-L. Viovy, "Structural plasticity of single chromatin fibers revealed by torsional manipulation," Nat. Struct Mol. Biol., vol.13, no. 5, pp. 444-450, May. 2006.

[5] J. Gore, Z. Bryant, M. D. Stone, M. Nöllmann, N. R. Cozzarelli, and C. Bustamante, "Mechanochemical analysis of DNA gyrase using rotor bead tracking," Nature, vol. 439, no. 7072, pp. 100-104, Jan. 2006.

[6] O. Chaudhuri, S. H. Parekh, and D. A. Fletcher, "Reversible stress softening of actin networks," Nature, vol. 445, no. 7125, pp. 295-298, Jan. 2007.

[7] T. Hawkins, M. Mirigian, M. S. Yasar, and J. L. Ross, "Mechanics of microtubules," J. Biomech., vol. 43, no. 1, pp. 23-30, Jan. 2010.

[8] F. Amblard, B. Yurke, A. Pargellis, and S. Leibler, "A magnetic manipulator for studying local rheology and micromechanical properties of biological systems," Rev. Sci. Instrum., vol. 67, no. 3, pp. 818-827, 1996.

[9] C. Gosse and V. Croquette, "Magnetic tweezers: Micromanipulation and force measurement at the molecular level," Biophys. J., vol. 82, no. 6, pp. 3314-3329, 2002.

[10] R. Simmons, J. Finer, S. Chu, and J. Spudich, "Quantitative measurements of force and displacement using an optical trap," Biophys. J., vol. 70, no. 4, pp. 1813-1822, 1996.

[11] E. L. Florin, V. T. Moy, and H. E. Gaub, "Adhesion forces between individual ligand-receptor pairs," Science, vol. 264, no. 5157, pp. 415417, Apr. 1994.

[12] A. Ishijima, T. Doi, K. Sakurada, and T. Yanagida, "Sub-piconewton force fluctuations of actomyosin in vitro," Nature, vol. 352, pp. 301-306, 1991.

[13] F. Beyeler, A. Neild, S. Oberti, D. Bell, Y. Sun, J. Dual, and B. Nelson, "Monolithically fabricated microgripper with integrated force sensor for manipulating microobjects and biological cells aligned in an ultrasonic field," J. Microelectromech. Syst., vol. 16, no. 1, pp. 7-15, 2007.

[14] K. Kim, X. Liu, Y. Zhang, and Y. Sun, "Nanonewton force-controlled manipulation of biological cells using a monolithic MEMS microgripper with two-axis force feedback," J. Micromech. Microeng., vol. 18, no. 5, p. 055013, Apr. 2008.

[15] G. Hashiguchi, T. Goda, M. Hosogi, K. Hirano, N. Kaji, Y. Baba, K. Kakushima, and H. Fujita, "DNA manipulation and retrieval from 421

422 423 424 425 426 427 428 431 432 433 434 436 437 438 439 440 441 442 443 444 445 446 447 448 449 450 451 452 453 454 455 456 457 458 459 460 461 462 463 464 465 466 467 468 469 473 .4. . 9 
an aqueous solution with micromachined nanotweezers," Anal. Chem., vol. 75 , no. 17 , pp. 4347-4350, 2003

[16] M. Kumemura, D. Collard, N. Sakaki, C. Yamahata, M. Hosogi, G. Hashiguchi, and H. Fujita, "Single-DNA-molecule trapping with silicon nanotweezers using pulsed dielectrophoresis," J. Micromech. Microeng., vol. 21, p. 054020, 2011.

[17] C. Yamahata, D. Collard, B. Legrand, T. Takekawa, M. Kumemura, G. Hashiguchi, and H. Fujita, "Silicon nanotweezers with subnanometer resolution for the micromanipulation of biomolecules," J. Microelectromech. Syst., vol. 17, no. 3, pp. 623-631, 2008.

[18] M. Kumemura, D. Collard, S. Yoshizawa, D. Fourmy, N. Lafitte, L. Jalabert, S. Takeuchi, T. Fujii, and H. Fujita, "Direct bio-mechanical sensing of enzymatic reaction on DNA by silicon nanotweezers," in Proc. IEEE 23rd Int. Conf. Microelectromech. Syst., Hong Kong, 2010, pp. 915-918.

[19] S. Smith, Y. Cui, and C. Bustamante, "Overstretching B-DNA: The elastic response of individual double-stranded and single-stranded DNA molecules," Science, vol. 271, no. 5250, pp. 795-799, 1996.

[20] N. Lafitte, M. Kumemura, L. Jalabert, D. Collard, and H. Fujita, "RealTime sensing of molecule binding on DNA with silicon nanotweezers," in Proc. 15th Int Conf. Miniaturized Syst. Chem. Life Sci., Seattle, WA, USA, 2011, pp. 389-372.

[21] Y. Sun, B. J. Nelson, D. P. Potasek, and E. Enikov, "A bulk microfabricated multi-axis capacitive cellular force sensor using transverse comb drives," J. Micromech. Microeng., vol. 12, no. 6, p. 832, 2002.

[22] W. Tang, T.-C. H. Nguyen, and R. Howe, "Laterally driven resonant microstructures," Sens. Actuators, vol. 20, pp. 25-32, 1989.

[23] G. Zhou and P. Dowd, "Tilted folded-beam suspension for extending the stable travel range of comb-drive actuators," J. Micromech. Microeng., vol. 13 , no. 2 , pp. $178-183,2003$.

[24] T. Clark and R. Howe, "An integrated CMOS micromechanical resonator high-Q oscillator," IEEE J. Solid-State Circuits, vol. 34, no. 4, pp. 440455, Apr. 1999.

[25] R. Legtenberg, A. Groeneveld, and M. Elwenspoek, "Comb-drive actuators for large displacements," J. Micromech. Microeng., vol. 6, no. 3, pp. 320-329, 1996.

[26] Y. Sun, S. N. Fry, D. P. Potasek, D. J. Bell, and B. J. Nelson, "Characterizing fruit fly flight behavior using a microforce sensor with a new comb-drive configuration," J. Micromech. Syst., vol. 14, pp. 4-11, 2005.

[27] M. Bao, Analysis and Design Principles of MEMS Devices. New York, NY, USA: Elsevier, 2005.

[28] N. Lafitte, "Modeling and control of MEMS tweezers for the characterizations of enzymatic reactions on DNA molecules," Ph. D. dissertation, Université de Franche-Comté, Besançon, France, Apr. 2012.

[29] D. Collard, C. Yamahata, B. Legrand, T. Takekawa, M. Kumemura, N. Sakaki, G. Hashiguchi, and H. Fujita, "Towards mechanical characterization of biomolecules by MNEMS tools," IEEJ Trans. Electr. Electron. Eng., vol. 2, no. 3, pp. 262-271, Apr. 2007.

[30] D. Collard, "Silicon nanotweezers for biomechanical and bioelectrical assays," Front. Biosci., vol. E5, pp. 955-965, Jun. 2013.

[31] M. C. Tarhan, D. Collard, L. Jalabert, M. Kumemura, N. Lafitte, Q. Delouvée, S. L. Karsten, and H. Fujita, "Continuous real-time monitoring of molecular detection by silicon nanotweezers-integrated microfluidic device," in Proc. 16th Int. Conf. Miniaturized Syst. Chem. Life Sci., Okinawa, Japan, Oct. 2012, pp. 1897-1899.

[32] M. Washizu and O. Kurosawa, "Electrostatic manipulation of DNA in microfabricated structures," IEEE Trans. Ind. Appl., vol. 26, no. 6, pp. 1165-1172, Nov/Dec. 1990.

[33] R. Pankov, "Fibronectin at a glance," J. Cell Sci., vol. 115, no. 20, pp. 3861-3863, Oct. 2002.

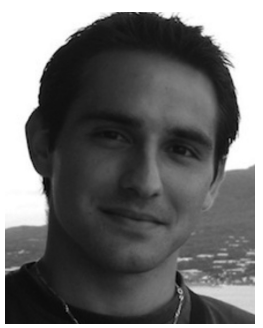

Nicolas Lafitte was born in Bordeaux, France, in 1983. He received the M.S. degree in electrical engineering speciality microelectronics from the University of Bordeaux 1, Bordeaux, and the graduate school ENSEIRB, Talence, France, in 2008, and the Ph.D. degree from the University of FrancheComté, Besançon, France, for his work on the modeling and the control of MEMS tweezers for characterizations of bioreactions on DNA molecules, in 2012. This work was conducted in LIMMS (CNRS/University of Tokyo joint laboratory) and in FEMTO-ST (CNRS/University of Franche-Comté). This publication deals with this work.

His current research interests include the MEMS integration for biological applications at the University of Tokyo, Japan.

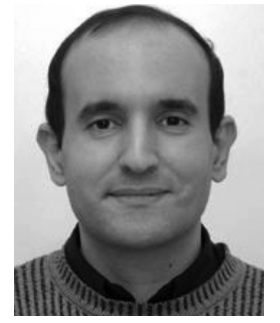

Yassine Haddab received the Engineering degree in electrical engineering from the University of Tizi-Ouzou, Tizi-Ouzou, Algeria, the M.S. degree from ENSMM, Besançon, France, and the Ph.D degree from the University of Franche-Comté, Besançon, France, in 2000. In 2012, he received the Habilitation a Diriger de Recherches degree from the University of Franche-Comté, Besançon.

Since 2002, he is an Associate Professor with ENSMM, Besançon, where he teaches control, microrobotics and embedded real-time systems. His research interests include the design, modeling, and control of high precision microrobots and microsystems. He also contributes to the development of microfactory concepts and new microrobots architectures.

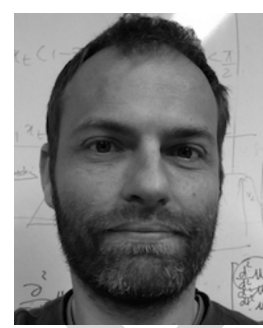

Yann Le Gorrec (M'XX) was graduated as engineer in "control, electronics, computer engineering"from the National Institute of Applied Sciences, Toulouse, France, in 1995, and received the Ph.D. degree from the National Higher School of Aeronautics and Aerospace, Supaero, Toulouse, in 1998.

From 1999 to 2008, he was an Associate Professor in Automatic Control at the Laboratory of Control and Chemical Engineering of Lyon Claude Bernard University, Villeurbanne, France. He worked on port Hamiltonian systems and their use for the modeling and control of irreversible and distributed parameter systems with an application to physico-chemical processes. Since september 2008, he has been a Professor with the National Engineering Institute in Mechanics and Microtechnologies. He is currently the Head of the COntrol DEsign research group of FEMTO-ST AS2M department. His research interests include robus control and self scheduled controller synthesis, the control of nonlinear systems, irreversible and infinite dimensional systems with an application to smart material-based actuators, and microactuators.

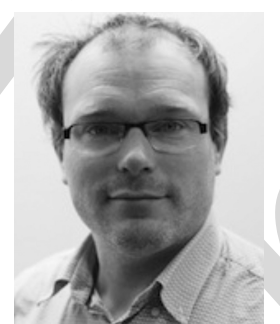

Hervé Guillou was born in Grenoble, France, in 1973. He studied fundamental physics from the University of Grenoble Alpes, Grenoble, France, the University of Karlsruhe, Karlsruhe, Germany, and at New York University, New York, NY, USA. He received the Master of Sciences degree from New York University and then a Ph.D. degree from the university of Grenoble Alpes, in 1998 and 2001, respectively.

Since 2004, he has been a Lecturer in physics with the University of Grenoble Alpes. His first research interests include low temperature physics and superconductivity. He moved, then, to the field of biophysics where his interests include cell architecture, cell and molecular force generation, and development of methods, instruments, and microsystems for applications in biophysics and medicine.

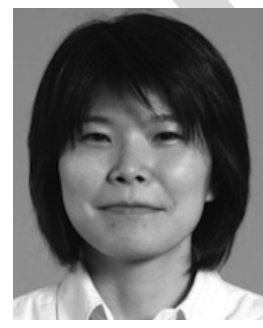

Momoko Kumemura was born in Kagoshima, Japan, in 1975. She received the M.S. degree in engineering from Tokushima University, Tokushima, Japan, and the Ph.D. degree in chemistry from Tokyo Metropolitan University, Tokyo, Japan, in 2002 and 2005, respectively.

She was a Postdoctoral Researcher in the Center for International Research on Micromechatronics, Institute of Industrial Science, The University of Tokyo (2005-2008 and 2010-2013) and in the Centre National de la Recherche Scientifique (20082010). Since 2014, she has been a Research Associate in Institute of Industrial Science, The University of Tokyo. She is currently researching microsystems for biological applications. 
Laurent Jalabert was born in L'Union, France, in 1974. He received the Ph.D. degree from the Université Paul Sabatier, Toulouse, France, in 2001 dealing with CMOS gate engineering and reliability of ultrathin oxides.

From 2001 to 2003, he joined LIMMS (CNRSUniversity of Tokyo joint laboratory), Tokyo, Japan, as a Postdoctoral Researcher granted from the Japanese Society for the Promotion of Science and he developed piezoresistive MEMS cantilever for metrology in high aspect ratio microholes. In 2004, he joined Institut National Polytechnique de Toulouse as a Research Engineer and worked at Laboratoire dAnalyse et dArchitecture des Systèmes on ICP-RIE plasma and alternative technologies (nanoimprint). Since 2007 till now, he is with the LIMMS as a CNRS Research Engineer hosted in Pr. Hiroyuki Fujita laboratory. His current research interests include atomic heat transfer in UHVTEM and MEMS fabrication (silicon nanotweezers, liquid-cells, etc.).

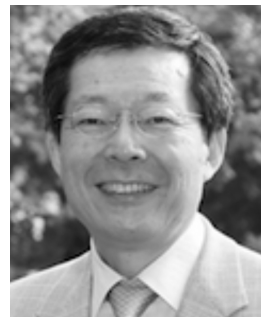

Hiroyuki Fujita (S'76-M'80) received B.S., M.S., 657 and Ph.D. degrees in electrical engineering from the 658 University of Tokyo, Tokyo, Japan, in 1975, 1977, 659 and 1980 , respectively.

Since 2000, he is the Director of the Center for 661 International Research on MicroMechatronics. Also, 662 since 1993, he has been a Professor, an Associate 663 Professor (1981-1993), and a Lecturer (1980-1981) 664 with the Institute of Industrial Science, the Univer- 665 sity of Tokyo. He is currently involved in the in- 666 vestigation of microelectromechanical systems fabri- 667 cated by IC-based processes and applications to optics, hard disk drives, and 668 bio/nanotechnology. His research interest includes autonomous distributed mi- 669 crosystems.

Dr. Fujita is a Fellow of the Institute of Electrical Engineers of Japan.

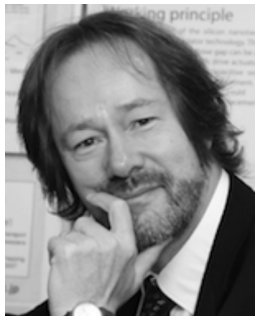

Dominique Collard (M'01) was born in Cambrai, France in 1958. He received the Engineering Degree from the Institut Supérieur dElectronique et du Numérique and the Ph.D. degree from the University of Lille, Lille, France, in 1980 and 1984, respectively.

From 1985 to 1986 , he was with the Toshiba VLSI Research Center, Kawasaki, Japan, as a Visiting Scientist. Since 1988, he has been with the Centre National de la Recherche Scientifique (CNRS), being alternatively with the Institut dElectronique, de Microélectronique et de Nanotechnologie, Lille, and with the Laboratory for Integrated MicroMechatronic Systems (LIMMS/CNRS-IIS), Tokyo. From August 2005, he joint a second time LIMMS where he was appointed as a Director in September 2007 and got a title of Project Professor of IIS, the University of Tokyo, Tokyo, Japan. In December 2011, he became Coordinator of EC/FP7 INCOLAB: EUJO-LIMMS aiming to open LIMMS to European partners and first EC laboratory in Japan. His current scientific interests include micro- and nano-systems for applications in biology and nanotechnology. He is the Author or Coauthor of more than 250 international publications.

Dr. Collard received the IBM price on intensive numerical calculation in 1990, the CNRS bronze medal in 1992, and was in 2004 Laureate of the French academic palms from Ministry of Higher Education and Research. 


\section{QUERIES}

Q1. Author: Please provide the full page range in Refs. [14], [16], and [21].

Q2. Author: Please provide the department name in Ref. [28].

Q3. Author: Please provide the year in which the author "Yann Le Gorrec" became a Member of the IEEE. 